\title{
Mangiferin Alleviates Mitochondrial ROS in Nucleus Pulposus Cells and Protects against Intervertebral Disc Degeneration via Suppression of NF- $\kappa$ B Signaling Pathway
}

\author{
Haichao Yu, ${ }^{1}$ Guowei Hou, ${ }^{2}$ Jiankang Cao, ${ }^{3}$ Yanyu Yin, ${ }^{4}$ Yunpeng Zhao ${ }^{(D,},{ }^{1}$ and Lei Cheng ${ }^{1}$ \\ ${ }^{1}$ Department of Orthopedic, Qilu Hospital, Cheeloo College of Medicine, Shandong University, Jinan, 250012 Shandong, China \\ ${ }^{2}$ Department of Orthopedic, PKU Care Luzhong Hospital, Zibo, 255499 Shandong, China \\ ${ }^{3}$ Department of Pain, Qilu Hospital, Cheeloo College of Medicine, Shandong University, Jinan, 250012 Shandong, China \\ ${ }^{4}$ Department of Orthopedic, Yucun Hospital of Xinwen Mining Group Co. Ltd., Taian, 271200 Shandong, China
}

Correspondence should be addressed to Yunpeng Zhao; zhaoyunpeng@qiluhospital.com

and Lei Cheng; chenglei@email.sdu.edu.cn

Received 17 November 2020; Revised 15 March 2021; Accepted 23 April 2021; Published 14 June 2021

Academic Editor: Ana Lloret

Copyright ( 2021 Haichao Yu et al. This is an open access article distributed under the Creative Commons Attribution License, which permits unrestricted use, distribution, and reproduction in any medium, provided the original work is properly cited.

\begin{abstract}
Intervertebral disc degeneration (IVDD), one of the most common clinical diseases worldwide, causes disc herniation and sciatica. Recent studies have identified the involvement of mitochondrial dysfunction, inflammatory responses, and extracellular matrix degradation in IVDD. Mangiferin is known to protect against various diseases by inhibiting oxidative stress, suppressing inflammation reaction, and relieving mitochondrial dysfunction. Whether mangiferin can alleviate IVDD remains to be elucidated. In the present study, human nucleus pulposus cells (HNPCs) and mouse intervertebral discs were cultured and stimulated with TNF- $\alpha$, with or without treatment of mangiferin. Moreover, we established a rat needle puncture model and injected mangiferin into the intervertebral discs to verify its protective effect on IVDD. Furthermore, the activity of the NF- $\kappa \mathrm{B}$ signaling pathway was tested in vitro. Our results indicated that mangiferin alleviated the inflammatory response and reversed the loss of major intervertebral disc components. Besides, mangiferin reduced reactive oxygen species production, ameliorated mitochondrial damage, and decreased the expression of apoptosis-related parameters in stimulation of TNF- $\alpha$. In addition, mangiferin antagonized the activation of the NF- $\kappa$ B signaling pathway induced by TNF- $\alpha$. Collectively, mangiferin antagonized mitochondrial ROS in NP cells and protected against IVDD by suppressing the activation of the NF- $\kappa$ B signaling pathway, which might provide a potential therapeutic instrument for IVDD.
\end{abstract}

\section{Introduction}

Approximately $84 \%$ of people are estimated to have low back pain (LBP) and $10 \%$ of LBP cases result in chronic disability $[1,2]$. According to recent studies, LBP is closely associated with intervertebral disc degeneration (IVDD), which interferes the structure and function of the intervertebral disc (IVD). Recent studies have reported critical roles for reactive oxygen species (ROS), oxidative stress, and subsequent mitochondrial dysfunction in the development of IVDD [3-5]. ROS exacerbate various pathological processes involved in IVDD, such as activating the NF- $\kappa$ B and MAPK signaling pathways, increasing inflammatory cytokine production, and promoting apoptosis and senescence in IVD cells [68]. Mitochondrial dysfunction is a main cause of ROS production, and mitochondria are also a predominant target of ROS. High levels of ROS lead to the gradual deterioration of mitochondrial function, which triggers excess catabolism in nucleus pulposus (NP) cells and increases inflammation in the microenvironment of the IVD [8].

Inflammation is reported to be a major contributor to IVDD [9]. TNF- $\alpha$ is a critical proinflammatory molecule involved in IVDD. TNF- $\alpha$ leads to a reduction in aggrecan and type II collagen (Col-2) levels and promotes the degradation of the extracellular matrix (ECM) by inducing the production of matrix metalloproteinases (MMPs) and a 
disintegrin and metalloproteinase with thrombospondin motifs (ADAMTSs) [10-13]. Moreover, TNF- $\alpha$ is known to promote ROS production and the release of various inflammatory cytokines, which potentially enhance cell apoptosis and senescence [14]. These pathological changes caused by TNF- $\alpha$ ultimately lead to the occurrence and development of IVDD.

Mangiferin (2-C- $\beta$-D-glucopyranosyl-1,3,6,7-tetrahydroxyxanthone), which has a C-glucosyl linkage with multiple - $\mathrm{OH}$ groups, possesses strong free radical-scavenging activity [15]. Mangiferin is extensively distributed in plants worldwide, but its principal and most accessible source is the mango tree. Mangiferin possesses a wide range of properties with pharmacological potential, including antioxidant, anti-inflammatory, antidiabetic, antihyperlipidemic, and antiatherogenic properties [16]. Mangiferin antagonizes oxidative stress and mitochondrial dysfunction in various pathological processes [17-19]. Mangiferin reduces artificially induced apoptosis and ECM degradation related to arthritis [20]. Additionally, mangiferin was shown to exert a protective effect on a rat spinal cord injury model by inhibiting the inflammatory response and apoptosis [21]. However, researchers have not clearly determined whether mangiferin plays a role in the development of IVDD. Building upon the results of previous studies, we will explore the role of mangiferin in preventing IVDD and then investigate the potential mechanisms involved.

\section{Materials and Methods}

2.1. Ethics Statement. In this study, human IVD tissues were obtained from 10 patients (4 males and 6 females; 18-30 years old) with IVDD (all with grade II IVDD) who underwent lumbar spine surgery at Qilu Hospital of Shandong University, Jinan, China. The degree of IVDD was assessed using the modified Pfirrmann grading system [22]. All patients involved in this study were given informed consent documents and voluntarily agreed to participate in this research, and this study was approved by the Medical Ethics Committee of Qilu Hospital of Shandong University. All animal experimental procedures were performed in accordance with the International Guiding Principles for Animal Research and were approved by the Laboratory Animal Centre of Shandong University.

\subsection{Primary Human Nucleus Pulposus Cell (HNPC) Isolation.} We collected the human IVD samples during spine surgeries. All procedures involved in the isolation and culturing of primary HNPCs were performed as previously reported [23]. We washed the blood from the IVD with precooled PBS. Then, we used a microscope to carefully remove the cartilage endplate and the annulus fibrosus and isolate the NP tissues, which were cut into fragments of approximately $2 \mathrm{~mm}$. The NP fragments were digested with trypsin for 20 minutes and then with type II collagenase for $8 \mathrm{~h}$ and filtered through a 200-mesh sieve. The isolated NP cells were seeded in DMEM/F12 (HyClone, USA) containing 10\% fetal bovine serum (FBS) (Gibco, USA), $50 \mathrm{mg} / \mathrm{ml}$ ascorbic acid, and $1 \%$ penicillin and streptomycin (HyClone, USA) at $37^{\circ} \mathrm{C}$ in an atmosphere containing $5 \% \mathrm{CO}_{2}$ and $95 \%$ air at $\mathrm{pH} 7.2$. The culture medium was replaced once every 3 days. All HNPCs were passaged when they reached approximately 80-90\% confluence, and the indicated experiments were subsequently conducted.

2.3. HNPC Culture. HNPCs were seeded in a 6-well plate $\left(1 \times 10^{6}\right.$ cells $\left./ \mathrm{ml}\right)$. Then, the cells were treated with PBS, TNF- $\alpha(20 \mathrm{ng} / \mathrm{ml})$ (PeproTech, USA), TNF $-\alpha(20 \mathrm{ng} / \mathrm{ml})$ + mangiferin $(100 \mu \mathrm{M} / \mathrm{ml})$ (MedChemExpress, China), and $\mathrm{TNF}-\alpha(20 \mathrm{ng} / \mathrm{ml})+$ mangiferin $(500 \mu \mathrm{M} / \mathrm{ml})$.

2.4. Mouse IVD Isolation and Culture. All surgical procedures were performed under sterile conditions. The specimens of mouse spines were obtained from 10-week-old mice. After complete dissection of the spine and removal of the surrounding soft tissues, the lumbar spine was cut to a length of $5 \mathrm{~mm}$ while maintaining the integrity of the IVD. The lumbar spines of the mice were soaked in $100 \mathrm{U} / \mathrm{ml}$ penicillin/streptomycin for 30 minutes. The IVD tissues were incubated and stimulated with PBS $(n=7)$ or TNF- $\alpha$ $(20 \mathrm{ng} / \mathrm{ml}, n=7)$ in the presence or absence of mangiferin $(100 \mu \mathrm{M} / \mathrm{ml}, n=7 ; 500 \mu \mathrm{M} / \mathrm{ml}, n=7)$ for 7 days [24]. All IVD tissues were collected for use in subsequent experiments.

2.5. Rats. Three-month-old Sprague-Dawley rats were purchased from the Animal Center of Shandong University. All animals were housed under controlled identical, standard specific pathogen-free (SPF) environmental conditions $\left(23 \pm 2^{\circ} \mathrm{C}, 12 \mathrm{~h}\right.$ light/dark cycle) with free access to food and allowed to move freely. Local administration of mangiferin into the rat caudal disc via puncture was performed as previously reported [25]. Briefly, $2 \mu \mathrm{l}$ of PBS $(n=5)$ with or without $0.2 \mu \mathrm{g}$ of mangiferin $(0 \mu \mathrm{g}, n=5 ; 0.2 \mu \mathrm{g}, n=5)$ was delivered into the punctured disc through an intradiscal injection via a 33-gauge Hamilton syringe (Hamilton Co., NV, USA) 3 days after puncture.

2.6. Real-Time PCR Analysis. HNPCs were cultured for 1 or $24 \mathrm{~h}$ using the methods described above to detect different indicators [23]. TRIzol reagent (Takara Bio, Japan) was used to extract total RNA from the HNPCs that had been cocultured with $20 \mathrm{ng} / \mathrm{ml}$ TNF- $\alpha$ and different concentrations of mangiferin. A cDNA synthesis kit (Toyobo, Japan) was used to reverse transcribe identical amounts of RNA into cDNAs according to the manufacturer's instructions. Real-time PCR was performed with SYBR Green PCR Master Mix (Toyobo, Japan) on a thermal cycler (Roche, Switzerland); the results were normalized to GAPDH. The specific PCR products for each gene were confirmed by performing a melting curve analysis. We used the mean from the control group as value 1 . The relative gene expression levels were calculated using the formula $2^{-\Delta \Delta \mathrm{Ct}}$. The sequence-specific primers used in the present study are listed in Table 1.

2.7. Western Blotting. HNPCs were cultured for 1 or $48 \mathrm{~h}$ using the methods described above to detect different indicators by Western blotting [23]. Proteins were extracted from HNPCs and mouse IVD tissues from each treatment group. Equal amounts of protein were separated on $10 \%$ and $12 \%$ 
TABle 1: Primers for real-time PCR.

\begin{tabular}{|c|c|c|c|}
\hline Source & Target & Forward primer, $5^{\prime}-3^{\prime}$ & Reverse primer, $5^{\prime}-3^{\prime}$ \\
\hline \multirow{10}{*}{ Human } & $\mathrm{COX}-2$ & GGAACTTTCTGGTCCCTTCAG & TGTGTTTGGAGTGGGTTTCA \\
\hline & iNOS & GCCAAGCTGAAATTGAATGAGGA & TTCTGTGCCGGCAGCTTTAAC \\
\hline & MMP-13 & TGCTGCATTCTCCTTCAGGA & ATGCATCCAGGGGTCCTGGC \\
\hline & ADAMTS-5 & GAACATCGACCAACTCTACTCCG & CAATGCCCACCGAACCATCT \\
\hline & Collagen-II & TGGACGATCAGGCGAAACC & GCTGCGGATGCTCTCAATC \\
\hline & Aggrecan & ACTCTGGGTTTTCGTGACTCT & ACACTCAGCGAGTTGTCATGG \\
\hline & Bcl-2 & AACATCGCCCTGTGGATGAC & AGAGTCTTCAGAGACAGCCAGGAG \\
\hline & Bax & CCCGAGAGGTCTTTTTCCGAG & CCAGCCCATGATGGTTCTGAT \\
\hline & c-caspase-3 & GACTCTGGAATATCCCTGGACAACA & AGGTTTGCTGCATCGACATCTG \\
\hline & $\mathrm{NF}-\kappa \mathrm{B}_{1}$ & TATTTGAAACACTGGAAGCACG & CCGGAAGAAAAGCTGTAAACAT \\
\hline
\end{tabular}

acrylamide gels using SDS-PAGE and subsequently transferred to polyvinylidene difluoride (PVDF) membranes (Millipore, USA). After an incubation with $5 \%$ nonfat milk or $5 \%$ BSA for $1 \mathrm{~h}$ at room temperature, the membranes were incubated with the following primary antibodies (diluted $1: 500-1: 1000)$ at $4^{\circ} \mathrm{C}$ for $12 \mathrm{~h}$ : rabbit anti-iNOS (NB300605 Novus, UK), rabbit anti-COX-2 (ab179800, Abcam), rabbit anti-ADAMTS-5 (ab41037, Abcam), rabbit anticollagen-II (ab34712, Abcam), mouse anti-aggrecan (ab3778, Abcam), rabbit anti-Bcl-2 (AF6139, Affinity), rabbit anti-MMP-13 (AF5355, Affinity), rabbit anti-mitochondrial transcription factor A (TFAM) (AF0531, Affinity), rabbit anti-Optic Atrophy 1 (OPA1) (DF8587, Affinity), rabbit anti-Dynamin-related protein 1 (Drp1) (DF7037, Affinity), rabbit anti-cleaved-caspase-3 (c-caspase-3) (AF7022, Affinity), rabbit anti-Bax (\#2772, Cell Signaling Technology), rabbit anti-I $\kappa \mathrm{B} \alpha$ (\#9242, Cell Signaling Technology), rabbit antiphosphorylated $\mathrm{I} \kappa \mathrm{B} \alpha(\mathrm{pI} \kappa \mathrm{B} \alpha)(\# 2859$, Cell Signaling Technology), rabbit anti-p65 (\#8242, Cell Signaling Technology), and rabbit anti-phosphorylated p65 (pp65) (\#3033, Cell Signaling Technology). PVDF membranes were also incubated with a rabbit anti-GAPDH antibody $(1: 5000$, Proteintech, USA) to ensure equal protein loading. After washes with Tris-buffered saline- (TBS-) Tween 20, the membranes were then incubated with the secondary antibody $(1: 5000$, Cell Signaling Technology, USA) for $1 \mathrm{~h}$, and the immunolabeled bands were detected using a Fluor Chem E Chemiluminescent Western Blot Imaging System (Amersham Imager 600, GE Amersham, USA). The data were analyzed using the ImageJ software (National Institutes of Health, USA).

2.8. X-Ray and Magnetic Resonance Imaging (MRI) Analyses. Seven days after the initial puncture, each group of rats was randomly selected to undergo X-ray and MRI scans before sacrifice [25]. The rats were maintained in a supine position with their tails straight for placement on a molybdenum target radiographic-image unit (GE, Boston, MA, USA). Radiographs were captured at a collimator-to-film distance of $66 \mathrm{~cm}$, an exposure of $63 \mathrm{mAs}$, and a penetration power of $35 \mathrm{kV}$. We performed MRI using a $1.5 \mathrm{~T}$ system (GE) to obtain T2-weighted images (repetition time: $3000 \mathrm{~ms}$; echo time: $80 \mathrm{~ms}$; field of view: $200 \mathrm{~mm}^{2}$; slice thickness: $1.4 \mathrm{~mm}$ ) in the coronal plane. All the radiographic images were saved in a Neusoft PACS/RIS DICOM 3.0 medical imaging system (Neusoft, Jinan, China). The IVD height and the adjacent upper and lower vertebral body heights were measured using Neusoft PACS/RIS measuring tools, and the disc height index (DHI) was calculated from these values.

2.9. Immunohistochemical (IHC) Staining and Hematoxylin and Eosin (HE) Staining. The IVD tissues collected from mice and rats in each treatment group were immersed in $4 \%$ paraformaldehyde for $72 \mathrm{~h}$ and then subjected to decalcification, after which they were embedded in paraffin and cut into $5 \mu \mathrm{m}$ sections. Trypsin (0.125\%, Gibco, Waltham, USA) was used for antigen retrieval, and 3\% hydrogen peroxide was used to eliminate endogenous peroxidase activity. All primary antibodies were diluted in $1 \times$ antibody dilution buffer $(1 \times$ PBS with $10 \%$ v/v normal donkey serum (Solarbio, Beijing, China) and 0.01\% Proclean (Beyotime Biotechnology, Shanghai, China)), and the serial sections were incubated with primary antibodies (rabbit anti-collagen-II, rabbit anti-MMP-13, and mouse anti-aggrecan; all $1: 100$, Abcam, UK) at $4^{\circ} \mathrm{C}$ for $12 \mathrm{~h}$. Then, the sections were incubated with goat anti-rabbit and anti-mouse immunoglobulin- (IgG-) horseradish peroxidase (HRP) secondary antibodies ( $1: 200$, ZSGB-Bio, Beijing, China) for 60 minutes at room temperature. HE staining was performed according to the manufacturer's protocol. An IX71-SIF microscope (Olympus, Tokyo, Japan) was used to obtain the images.

2.10. Immunofluorescence (IF) Staining. HNPCs were seeded on cell coverslips and cultured with PBS, TNF- $\alpha(20 \mathrm{ng} / \mathrm{ml})$, $\mathrm{TNF}-\alpha(20 \mathrm{ng} / \mathrm{ml})+$ mangiferin $(100 \mu \mathrm{M} / \mathrm{ml})$, or $\mathrm{TNF}-\alpha$ $(20 \mathrm{ng} / \mathrm{ml})+$ mangiferin $(500 \mu \mathrm{M} / \mathrm{ml})$ for $48 \mathrm{~h}$ [26] before the levels of the iNOS, COX-2, MMP-13, and Col-2 proteins were detected. The cells were also cultured with PBS, TNF $-\alpha(20 \mathrm{ng} / \mathrm{ml})+$ mangiferin $(100 \mu \mathrm{M} / \mathrm{ml})$, or TNF $-\alpha(20$ $\mathrm{ng} / \mathrm{ml})+$ mangiferin $(500 \mu \mathrm{M} / \mathrm{ml})$ for $1 \mathrm{~h}$, and the level of the NF- $\kappa$ B pp 65 protein was detected. The cells were washed 3 times with PBS, fixed with 4\% paraformaldehyde for 20 minutes, permeabilized with $0.2 \%$ Triton X-100 for 15 minutes, and blocked with $1 \%$ BSA for 30 minutes at room temperature. Then, the cells were incubated with rabbit anti-iNOS ( $1: 100$, Novus, UK), rabbit anti-COX-2, rabbit anti-MMP-13, rabbit anti-collagen-II (all 1:100, Abcam, 
UK), rabbit anti-NF- $\kappa$ B p65 (1 : 100, AF5006, Affinity, USA), and rabbit anti-NF- $\kappa$ B pp65 ( $1: 100$, AF2006, Affinity, USA) primary antibodies for $12 \mathrm{~h}$ at $4{ }^{\circ} \mathrm{C}$. Afterwards, the cells were incubated with a fluorescently labeled goat anti-rabbit immunoglobulin (IgG) secondary antibody (1:50, ZSGB-Bio, Beijing, China) for $1 \mathrm{~h}$ at room temperature.

Trypsin (0.125\%, Gibco, USA) was used for antigen repair of IVD tissues in mice, and 3\% hydrogen peroxide was used to eliminate endogenous peroxidase activity. All primary antibodies were diluted in $1 \times$ antibody dilution buffer $(1 \times$ PBS with 10\% v/v normal donkey serum (Solarbio, Beijing, China) and $0.01 \%$ Proclean (Beyotime Biotechnology, Shanghai, China)), and the mouse IVD tissues were incubated with primary antibodies (rabbit anti-COX-2 and MMP-13, all $1: 100$, Abcam, UK) at $4^{\circ} \mathrm{C}$ for $12 \mathrm{~h}$. Then, the tissues were incubated with a fluorescently labeled goat anti-rabbit IgG secondary antibody (1:50, ZSGB-Bio, Beijing, China) for $1 \mathrm{~h}$ at room temperature. The images were captured using a fluorescence microscope (Ti2-U, Nikon, Japan).

2.11. Safranin $O$ and Fast Green Staining. Safranin O and fast green staining were performed to determine changes in proteoglycans. The mouse and rat IVD sections were stained with a Safranin O kit (Solarbio, China) according to the manufacturer's recommended procedure. An IX71-SIF microscope (Olympus, Tokyo, Japan) was used to capture the images.

2.12. TUNEL Assay. TUNEL staining of mouse IVD tissues from each treatment group cultured as described above for 7 days and HNPCs from each treatment group cultured as described above for $24 \mathrm{~h}$ [27] was performed using the TUNEL System (Elabscience, Wuhan, China) according to the manufacturer's protocol. The images were captured using a fluorescence microscope (Ti2-U, Nikon, Japan).

2.13. JC-1 Assay. HNPCs were cultured as described above for $24 \mathrm{~h}$ [27]. A JC-1 assay kit was used (Beyotime Biotechnology, China) to detect the mitochondrial membrane potential. In accordance with the manufacturer's instructions, primary HNPCs from each group cultured in 24-well plates were stained with the JC- 1 staining solution at $37^{\circ} \mathrm{C}$ for 20 minutes. Then, the cells in each well were washed twice with $1 \times$ JC- 1 staining buffer. The images were captured using a fluorescence microscope (Ti2-U, Nikon, Japan).

2.14. ROS Assay. HNPCs were cultured as described above for $24 \mathrm{~h}$ [27]. We used a ROS assay kit (Beyotime Biotechnology, China) to detect intracellular ROS levels. All procedures were performed according to the manufacturer's instructions. Briefly, after two washes with sterile PBS, HNPCs were stained with $10 \mu \mathrm{M}$ DCFDA at $37^{\circ} \mathrm{C}$ for 20 minutes in the dark and mixed every 15 minutes. Then, the HNPCs were washed three times with serum-free culture medium to reduce interference from excess DCFDA. The images were captured using a fluorescence microscope (Ti2-U, Nikon, Japan).
2.15. MitoTracker Assay. HNPCs were cultured according to the above method for $24 \mathrm{~h}$ [27], and MitoTracker staining was performed to visualize the mitochondria in the HNPCs of each experimental group. The procedure was performed in accordance with the instructions of the MitoTracker assay kit (MitoTracker Red CMXRos, Beyotime Biotechnology, China). HNPC nuclei were stained with DAPI, while the cytoskeleton was stained with phalloidin (green) (Solarbio, China). The images were captured using a fluorescence microscope (Ti2-U, Nikon, Japan).

2.16. Transmission Electron Microscopy (TEM). HNPCs were dehydrated in a graded series of ethanol solutions (50\%, 70\%, $80 \%, 90 \%, 95 \%, 100 \%$, and $100 \%$ ) for 15 minutes per solution and infiltrated with propylene oxide embedding medium overnight. Ultrathin sections $(50 \mathrm{~nm})$ were obtained using an EMUC7 ultramicrotome (Leica), poststained with uranyl acetate and lead citrate and visualized using a transmission electron microscope (HT7700; Hitachi, Japan).

2.17. Statistical Analysis. All data are presented as the mean values \pm standard deviations $(\mathrm{SD})$ and were analyzed using the GraphPad Prism v.5.0 software (GraphPad Software Inc., USA). Comparisons of various treatment groups were performed using analysis of variance (ANOVA) with Tukey's post hoc test. $P<0.05$ was considered statistically significant.

\section{Results}

3.1. Mangiferin Alleviated the TNF- $\alpha$-Induced Inflammatory Response in HNPCs. Previous research has shown that increased expression of inflammatory cytokines is an important factor leading to IVDD. Therefore, we investigated the role of mangiferin in the progression of IVDD by culturing HNPCs with PBS, TNF- $\alpha(20 \mathrm{ng} / \mathrm{ml}), \mathrm{TNF}-\alpha(20 \mathrm{ng} /$ $\mathrm{ml})+$ mangiferin $(100 \mu \mathrm{M} / \mathrm{ml}), \quad$ or $\mathrm{TNF}-\alpha(20 \mathrm{ng} / \mathrm{ml})+$ mangiferin $(500 \mu \mathrm{M} / \mathrm{ml})$ for $24 \mathrm{~h}$ to detect the mRNA level and $48 \mathrm{~h}$ to detect the protein level. After treatment, mRNA was extracted from the HNPCs, followed by real-time PCR. As indicated in Figures 1(a) and 1(b), after TNF- $\alpha$ stimulation, the expression levels of COX-2 and iNOS were increased by 2.74 and 29.31 times compared with the PBS group. Coculture with different concentrations of mangiferin $(100 \mu \mathrm{M} / \mathrm{ml}$ and $500 \mu \mathrm{M} / \mathrm{ml})$, the expression of these cytokines decreased by $82.16 \%$ and $83.75 \%$ and $97.19 \%$ and $97.52 \%$, respectively, compared with the TNF- $\alpha$ group. Next, total protein was extracted from treated HNPCs, and Western blotting was performed to detect the expression levels of COX-2 and iNOS. As shown in Figures 1(c)-1(e), the lowest expression levels of these inflammatory cytokines were detected in the PBS group and the highest levels were detected in the TNF- $\alpha$ group, and the protein levels of COX-2 and iNOS in the TNF- $\alpha$ group were 3.91 and 2.62 times higher than those in the PBS group. After treatment with different concentrations of mangiferin, the expression levels of these inflammatory cytokines decreased in a dosedependent manner, the levels of COX-2 and iNOS were reduced by $51.58 \%$ and $90.94 \%$ and $35.74 \%$ and $84.75 \%$, respectively. As shown in Figures 1(f)-1(i), as measured 


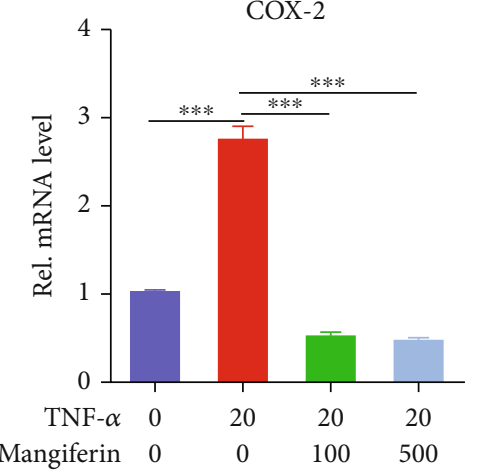

(a)

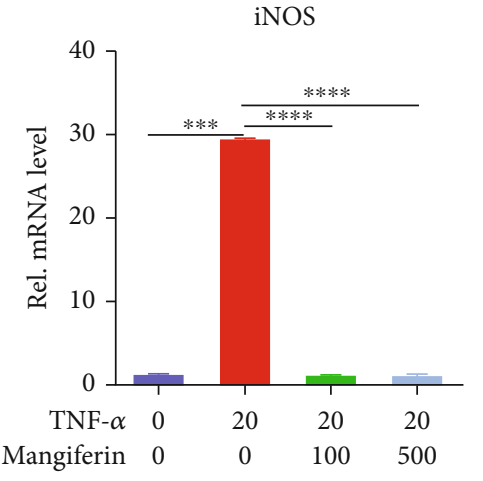

(b)

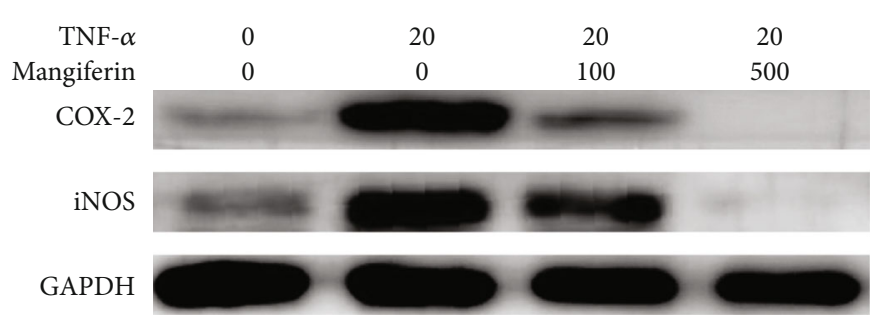

(c)

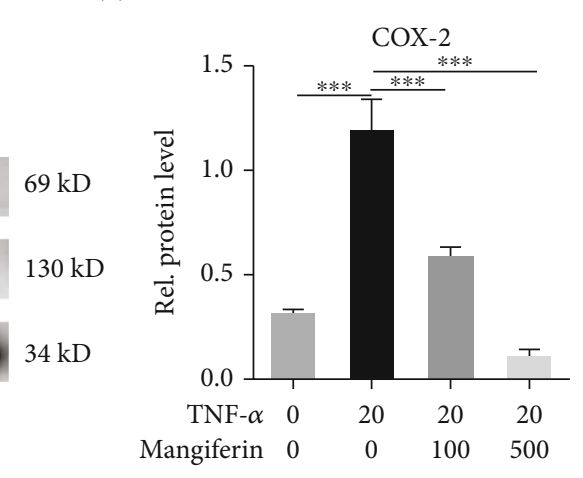

(d)

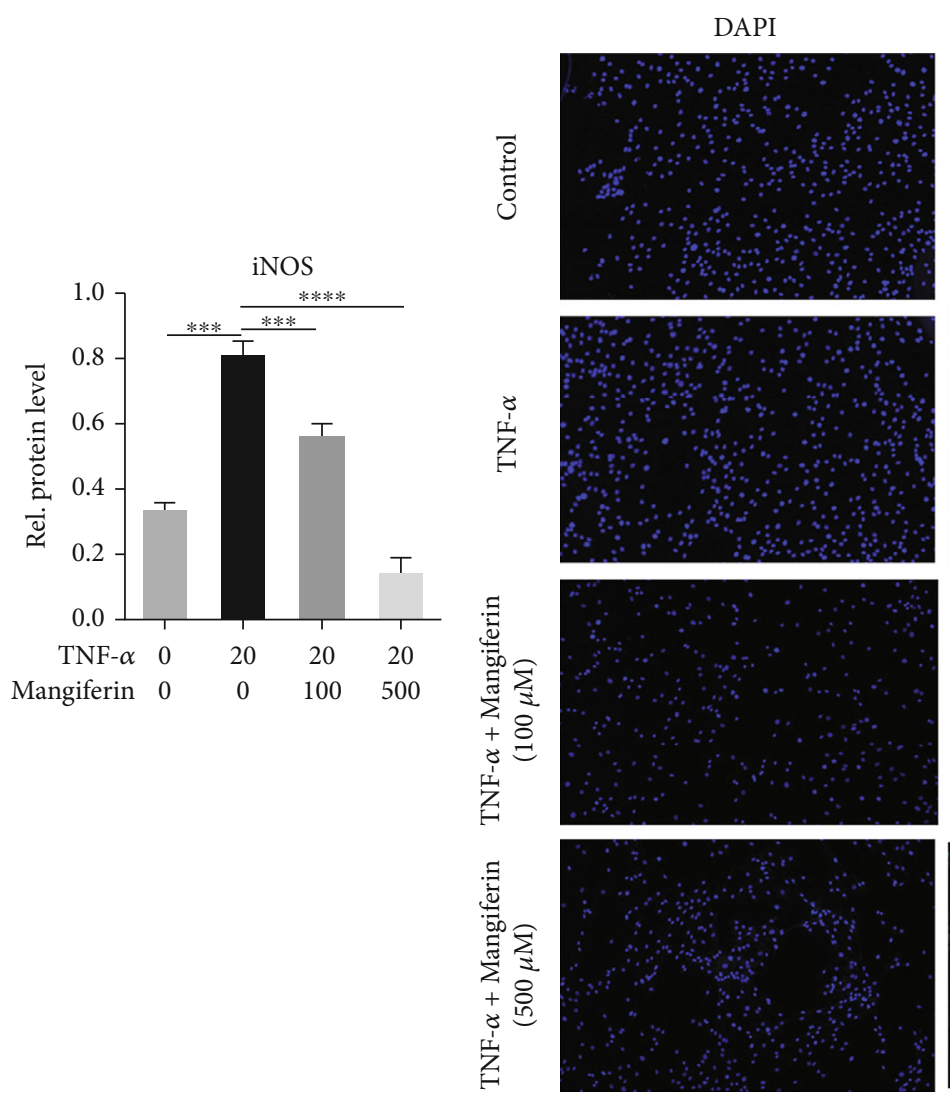

(e)
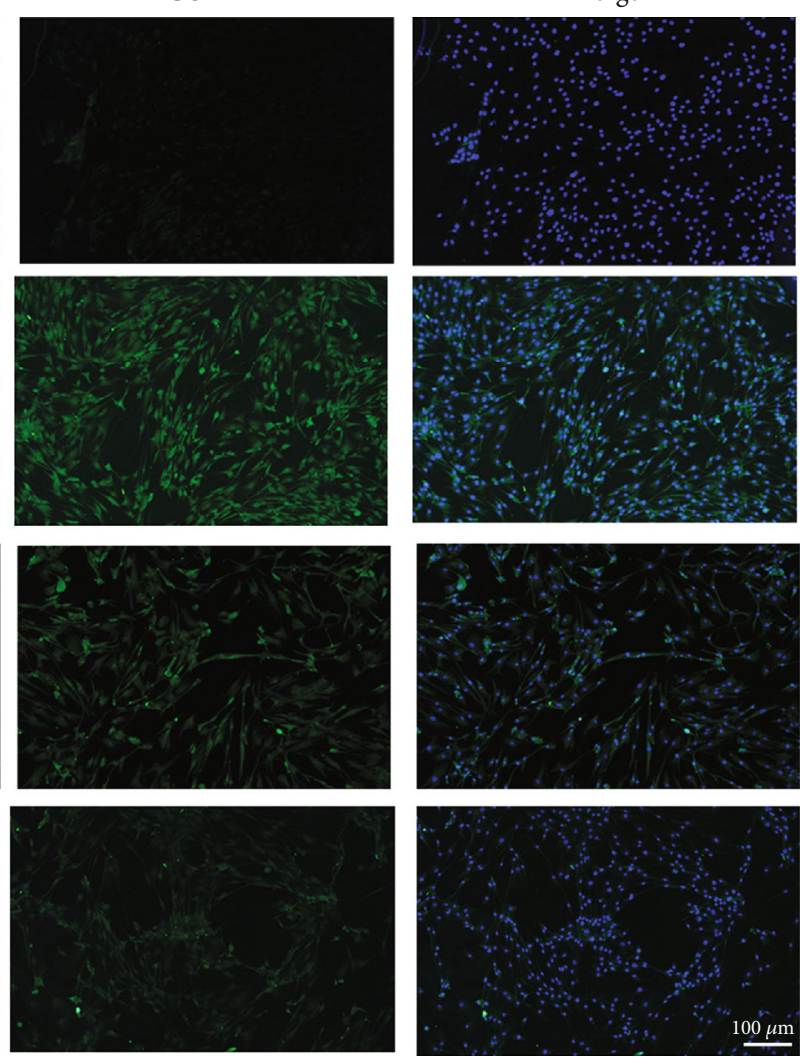

(f)

Figure 1: Continued. 

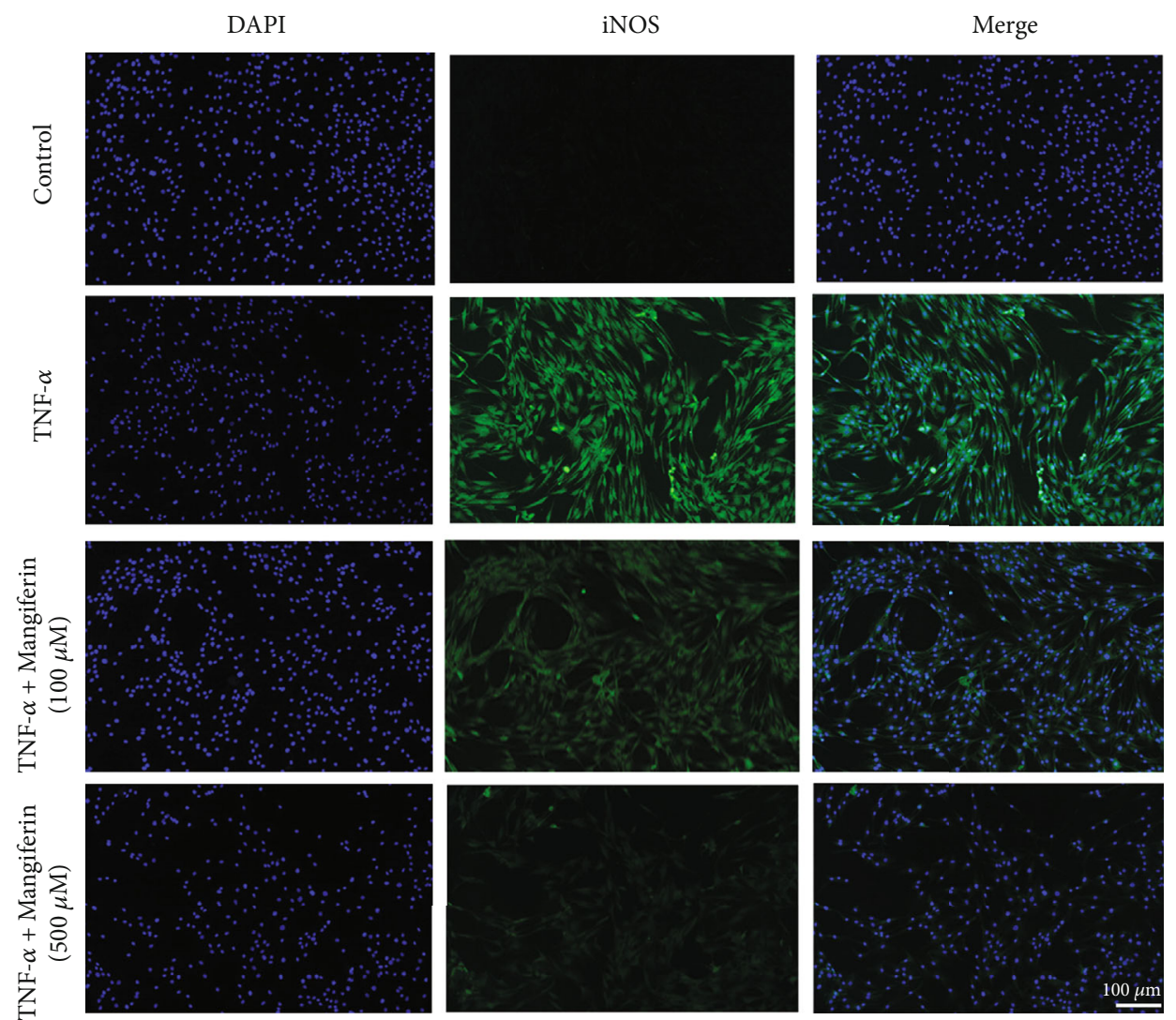

(g)

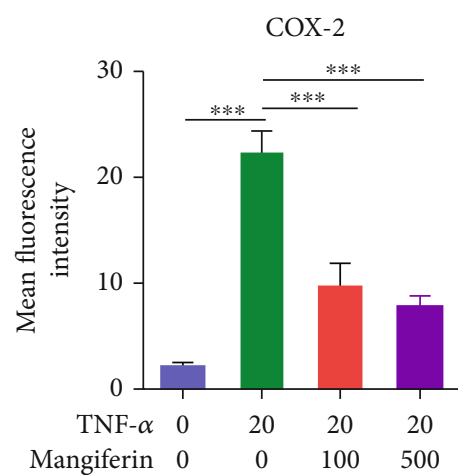

(h)

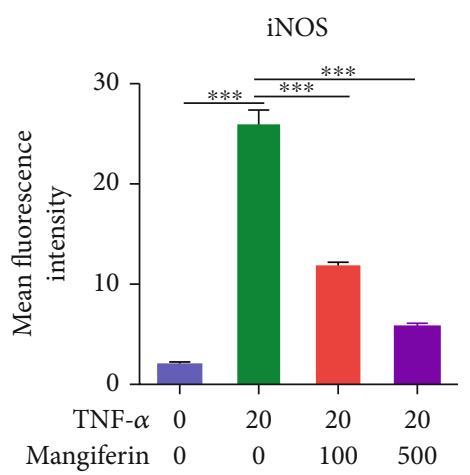

(i)

FIGURE 1: Mangiferin alleviated the inflammatory response in HNPCs. HNPCs were stimulated with PBS, TNF- $\alpha(20 \mathrm{ng} / \mathrm{ml}), \mathrm{TNF}-\alpha(20$ $\mathrm{ng} / \mathrm{ml})+$ mangiferin $(100 \mu \mathrm{M} / \mathrm{ml})$, or TNF $-\alpha(20 \mathrm{ng} / \mathrm{ml})+$ mangiferin $(500 \mu \mathrm{M} / \mathrm{ml})$. Total mRNA was extracted from each group, and the expression levels of (a) COX-2 and (b) iNOS were assayed using real-time PCR. Total protein was extracted from each group, and (c-e) the expression of COX-2 and iNOS was evaluated using Western blotting. (f-i) The expression levels of COX-2 and iNOS were detected using IF staining. Scale bar: $100 \mu \mathrm{m}$. All the experiments were repeated at least three times. Significant differences are indicated as follows: ${ }^{*} P<0.05,{ }^{* *} P<0.01,{ }^{* * *} P<0.001$, and ${ }^{* * * *} P<0.0001$.

using IF staining, in the four groups, the mean fluorescence intensities of COX-2 and iNOS were 1.94, 22.08, 9.38, and 7.57 and $1.91,25.92,11.72$, and 5.65, respectively. The statistical analysis of the mean fluorescence intensities indicated that the expression levels of COX-2 and iNOS in the TNF$\alpha$ group were 11.38 and 13.57 times higher than those in the PBS group, respectively. The mean fluorescence intensities of COX-2 and iNOS in the mangiferin $(100 \mu \mathrm{M} / \mathrm{ml})$ and mangiferin $(500 \mu \mathrm{M} / \mathrm{ml})$ groups decreased by $57.52 \%$ and $65.72 \%$ and $54.78 \%$ and $78.20 \%$, respectively, compared with those in the TNF- $\alpha$ group. Therefore, mangiferin reduced the TNF- $\alpha$-induced increases in the expression levels of COX-2 and iNOS, which alleviates the inflammatory response during the process of IVDD.

3.2. Mangiferin Restrained ECM Metabolism and Alleviated the Degeneration of HNPCs. As TNF- $\alpha$ promotes the expression of ADAMTSs and MMPs, leading to changes in the synthesis of ECM molecules and increased ECM degradation, the increased expression of MMP-13 and ADAMTS-5 in 
degenerative IVD tissues results in decreases in Col-2 and aggrecan levels $[28,29]$. Therefore, we established an HNPC inflammation model to mimic the pathological process and verified the role of mangiferin in IVDD. In this study, HNPCs were cultured and stimulated with PBS, TNF- $\alpha$ $(20 \mathrm{ng} / \mathrm{ml}), \quad \mathrm{TNF}-\alpha(20 \mathrm{ng} / \mathrm{ml})+$ mangiferin $(100 \mu \mathrm{M} / \mathrm{ml})$, or $\mathrm{TNF}-\alpha(20 \mathrm{ng} / \mathrm{ml})+$ mangiferin $(500 \mu \mathrm{M} / \mathrm{ml}) 24 \mathrm{~h}$ to detect the mRNA level and $48 \mathrm{~h}$ to detect the protein level. As shown in Figures 2(a) and 2(b), the levels of the aggrecan and Col-2 mRNAs decreased by $67.18 \%$ and $88.91 \%$ in TNF$\alpha$ group than those in PBS group, while the production of Col-2 and aggrecan gradually increased by 1.48 and 1.87 and 1.51 and 3.47 times after treatment with different concentrations of mangiferin. As shown in Figures 2(c) and 2(d), the mRNA levels of the MMP-13 and ADAMTS-5 after TNF- $\alpha$ stimulation were 4.07 and 4.25 times higher than those in PBS group, respectively. Compared with the TNF$\alpha$ group, the expression levels of these cytokines gradually decreased by $63.94 \%$ and $89.44 \%$ and $39.64 \%$ and $64.83 \%$ after treatment with $100 \mu \mathrm{M} / \mathrm{ml}$ and $500 \mu \mathrm{M} / \mathrm{ml}$ mangiferin. We extracted total proteins from HNPCs after cultivation with TNF- $\alpha$ and mangiferin to further explore the role of mangiferin in inhibiting the degeneration of HNPCs. As shown in Figures 2(e)-2(i), higher expression levels of MMP-13 and ADAMTS- 5 were detected in TNF- $\alpha$-stimulated HNPCs than in HNPCs treated with PBS alone, while lower expression levels of aggrecan and Col-2 were observed in TNF- $\alpha$-stimulated HNPCs than in PBS-treated HNPCs. The expression levels of MMP-13 and ADAMTS-5 were significantly decreased in response to the mangiferin treatment compared with those in the TNF- $\alpha$ group, while the expression levels of aggrecan gradually increased. Compared with TNF- $\alpha$ group, the expression of Col-2 was not increased after $100 \mu \mathrm{M} / \mathrm{ml}$ of mangiferin treatment, while the expression of Col-2 was increased after $500 \mu \mathrm{M} / \mathrm{ml}$ of mangiferin treatment. These results were verified by IF staining, as shown in Figures $2(\mathrm{j})-2(\mathrm{~m})$, in the four groups, and the statistical analysis of the mean fluorescence intensities indicated that the expression levels of MMP-13 in the TNF- $\alpha$ group were 2.73 times higher than those in the PBS group, and the expression levels of Col- 2 in the TNF- $\alpha$ group decreased by $63 \%$ than those in the PBS group. The mean fluorescence intensities of MMP-13 in the mangiferin $(100 \mu \mathrm{M} / \mathrm{ml})$ and mangiferin $(500 \mu \mathrm{M} / \mathrm{ml})$ groups decreased by $59.19 \%$ and $60.10 \%$ compared with those in the TNF- $\alpha$ group, and the expression levels of Col- 2 in the mangiferin $(100 \mu \mathrm{M} / \mathrm{ml})$ and mangiferin $(500 \mu \mathrm{M} / \mathrm{ml})$ groups were 1.02 and 2.05 times higher than those in the TNF- $\alpha$ group. Taken together, the experimental results shown in Figures 1 and 2 indicate that mangiferin may reduce the inflammatory response and the production of matrix-degrading enzymes in HNPCs and alleviate the loss of major IVD components that occurs during the development of IVDD.

3.3. Mangiferin Alleviated TNF- $\alpha$-Induced Oxidative Stress and Mitochondrial Dysfunction in HNPCs. We cultured HNPCs with PBS, TNF- $\alpha \quad(20 \mathrm{ng} / \mathrm{ml}), \quad$ TNF $-\alpha(20 \mathrm{ng} / \mathrm{ml})+$ mangiferin $(100 \mu \mathrm{M} / \mathrm{ml})$, or TNF $-\alpha(20 \mathrm{ng} / \mathrm{ml})+$ mangiferin $(500 \mu \mathrm{M} / \mathrm{ml})$ to verify whether mangiferin inhibits mitochondrial dysfunction caused by TNF- $\alpha$-induced oxidative stress in
HNPCs. We used TEM to observe the mitochondrial morphology of HNPCs. As shown in Figure 3(a), the mitochondria were swollen and deformed and exhibited disrupted mitochondrial cristae after HNPCs were treated with TNF- $\alpha$. However, treatment with different concentrations of mangiferin gradually reversed this phenomenon, which may prove that mangiferin plays a role in protecting against mitochondrial damage in HNPCs. OPA1, Drp1, and TFAM are biomarkers of mitochondrial morphology and function [30, 31], as shown in Figures 3(b)-3(e), and our study found that the mitochondrial dysfunction caused by TNF- $\alpha$ can be alleviated after treatment with mangiferin. As shown in Figures 3(f), 3(g), 3(j), and 3(k), JC-1 and MitoTracker staining were performed to detect the mitochondrial membrane potential, and our results further proved that mangiferin reversed the TNF- $\alpha$-induced mitochondrial damage in HNPCs. According to previous studies, ROS production increases in degenerative IVD tissue and forms a positive feedback loop that further promotes the production of ROS. In addition, mitochondria are the main target of ROS attack, and inhibiting the production of ROS may become an important part of IVDD treatment. As shown in Figures 3(h) and 3(i), the statistical analysis of the DCFDA indicated that the expression levels of ROS in the TNF- $\alpha$ group were 11.38 times higher than those in the PBS group. The DCFDA indicated that the expression levels of ROS in the mangiferin $(100 \mu \mathrm{M} / \mathrm{ml})$ and mangiferin $(500 \mu \mathrm{M} / \mathrm{ml})$ groups decreased by $80.52 \%$ and $91.66 \%$, respectively, compared with those in the TNF- $\alpha$ group.

HNPC apoptosis has been shown to play a pivotal role in the degeneration of the IVD, over the past few years, and apoptosis in the IVD has become a focus area of research [8]. Relevant studies have mainly investigated three apoptotic signaling pathways: the mitochondrial pathway, the death receptor pathway, and the endoplasmic reticulum pathway. Among these pathways, the mitochondrial pathway plays an important role in the apoptosis of IVD cells [32, 33]. After treating HNPCs using the method described above, we extracted the total RNA and proteins to examine markers of the mitochondrial apoptosis pathway. As illustrated in Figures 3(1)-3(r), compared with TNF- $\alpha$ group, after treatment with mangiferin at different concentrations, the mRNA expression levels of Bax and c-caspase- 3 decreased by $72.30 \%$ and $78.53 \%$ and $82.16 \%$ and $83.75 \%$, respectively, and increased the expression of Bcl-2 by 1.25 and 1.82 times, respectively. Consistent with the trend of mRNA, mangiferin can significantly decrease the protein levels of Bax and c-caspase- 3 , increase the protein level of $\mathrm{Bcl}-2$, and play a protective role in the inhibition of apoptosis. As shown in Figures 3(s)-3(w), TNF- $\alpha$ increased the number of TUNEL-positive HNPCs compared with the number detected in HNPCs treated with PBS alone, but different concentrations of mangiferin prevented the TNF- $\alpha$-induced increase in the number of TUNEL-positive HNPCs; furthermore, Hoechst 33342 staining also proved that mangiferin inhibited the apoptosis of HNPCs caused by TNF- $\alpha$.

\subsection{Mangiferin Protected against TNF- $\alpha$-Induced Degeneration} in Cultured Mouse IVD Tissues. We cultured mouse IVDs from the upper and lower vertebral bodies in vitro with PBS, 


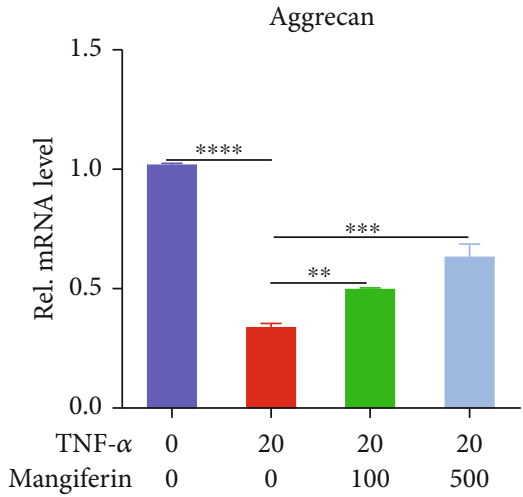

(a)

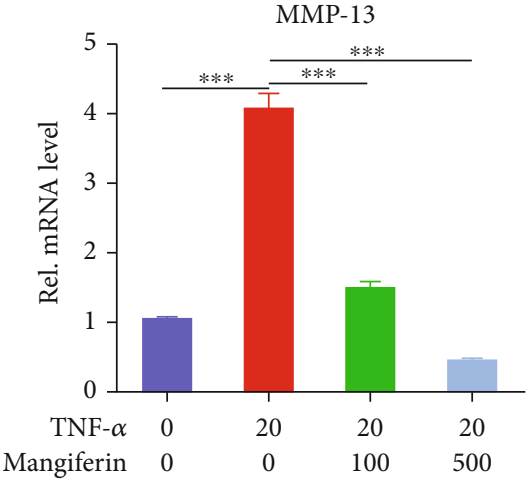

(c)

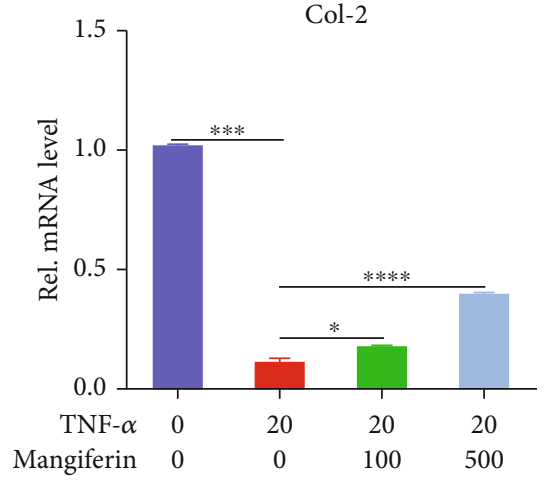

(b)

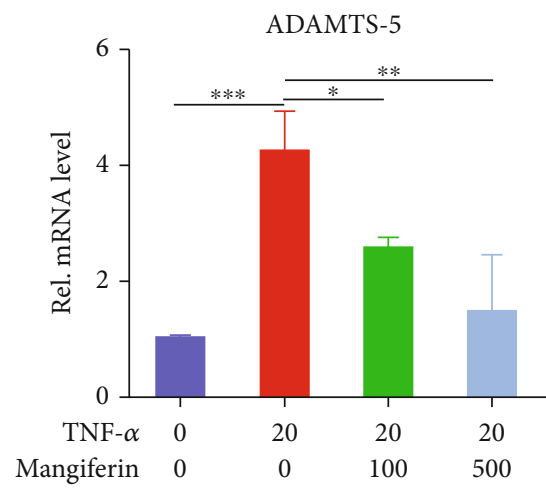

(d)

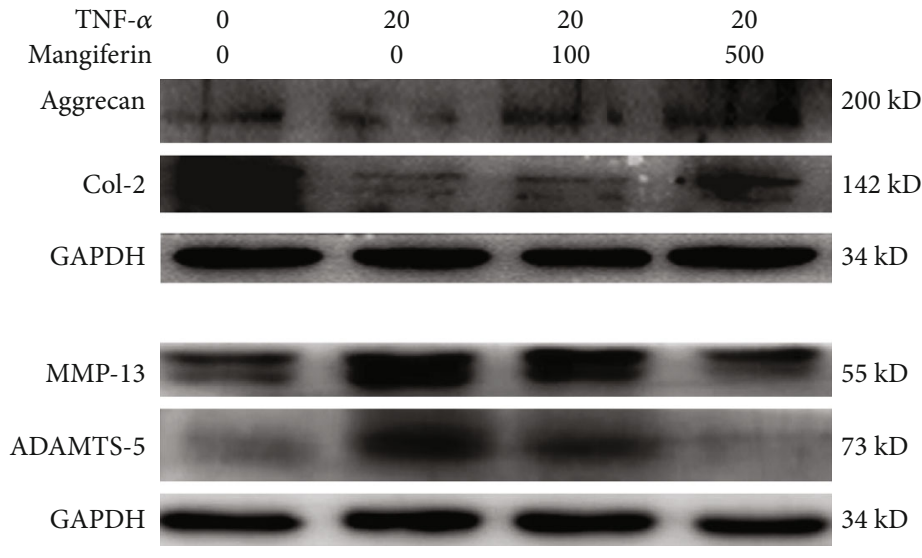

(e)

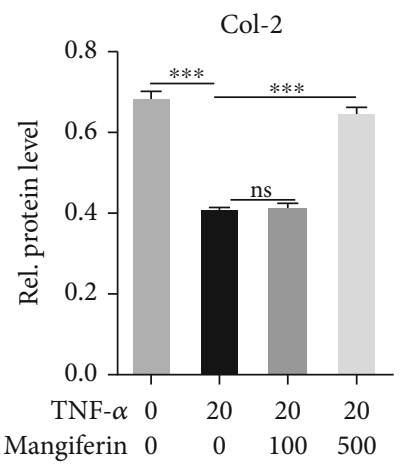

(g)

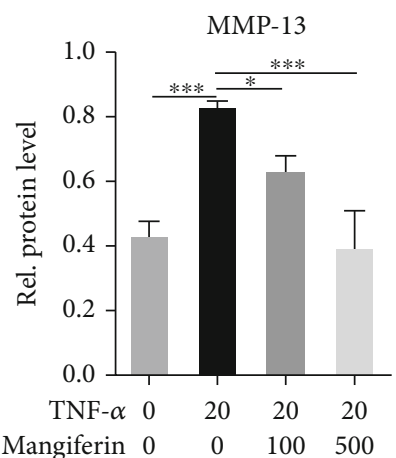

(h)

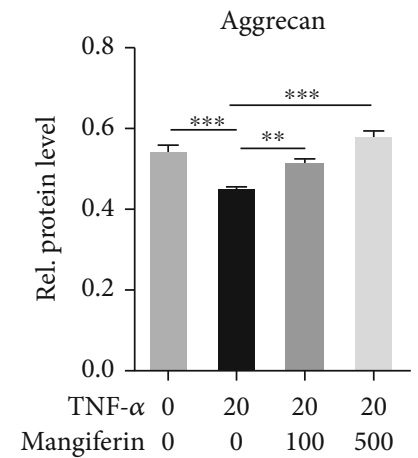

(f)

\footnotetext{
Figure 2: Continued.
} 


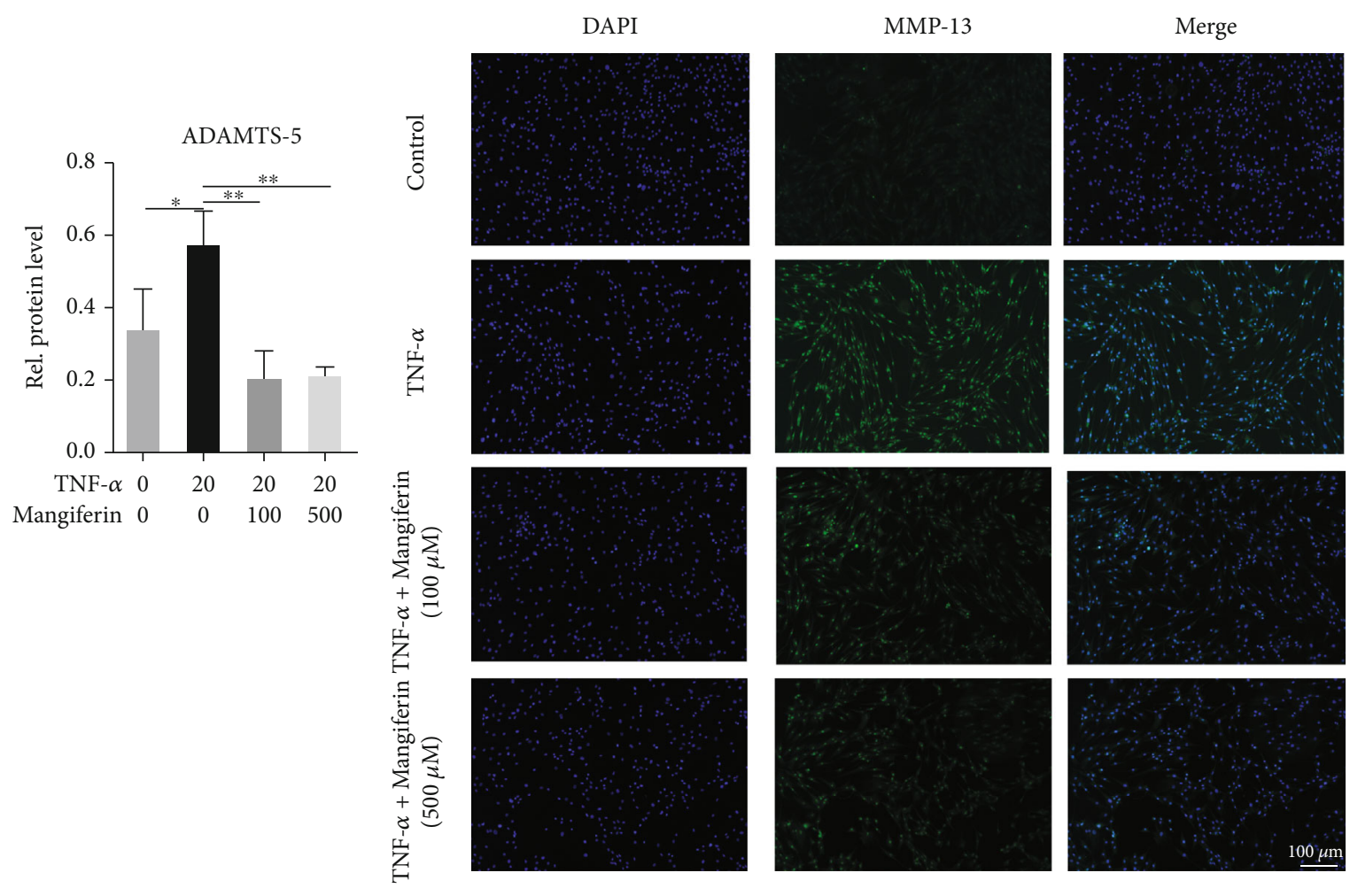

(i)
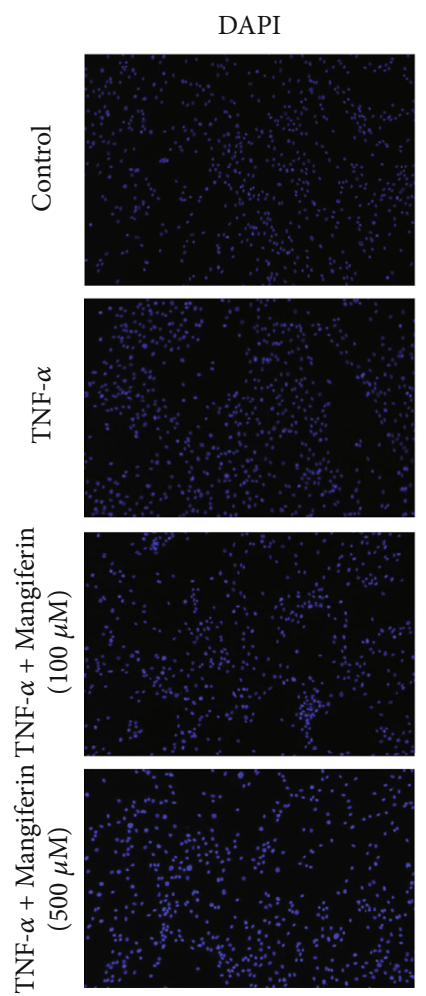

Col-2
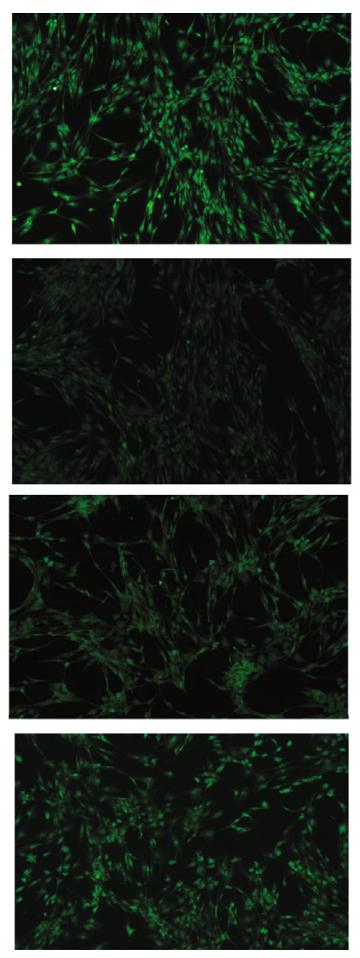

(k) (j)

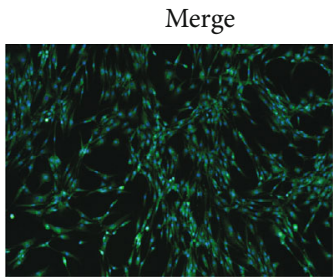

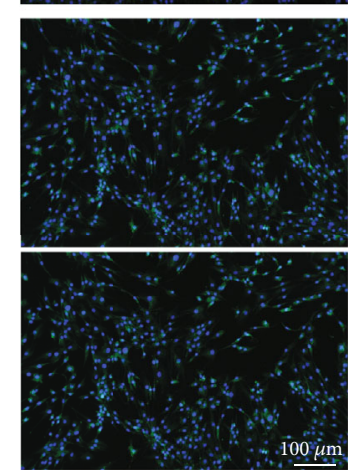

$100 \mathrm{\mu m}$

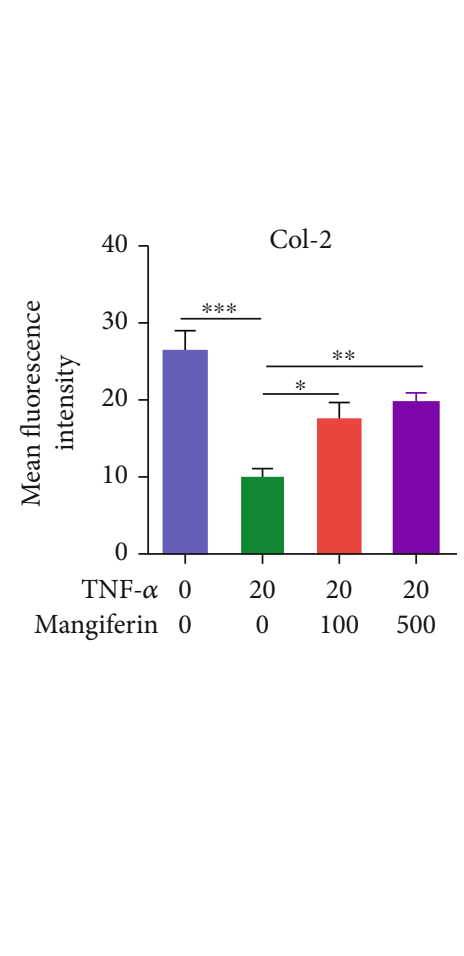

(1)

Figure 2: Continued. 


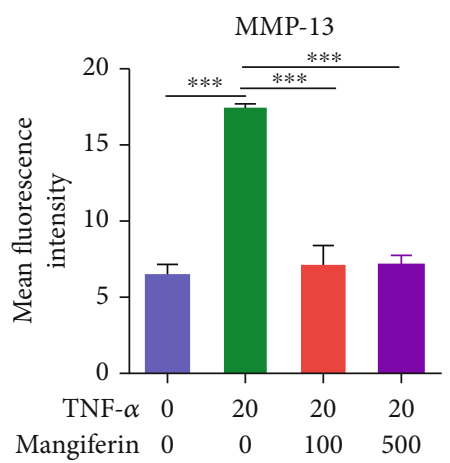

$(\mathrm{m})$

FIgURe 2: Mangiferin inhibited the TNF- $\alpha$-induced increase in the expression of catabolic enzymes and alleviated the loss of major ECM components. HNPCs were treated with PBS, TNF- $\alpha(20 \mathrm{ng} / \mathrm{ml}), \mathrm{TNF}-\alpha(20 \mathrm{ng} / \mathrm{ml})+$ mangiferin $(100 \mu \mathrm{M} / \mathrm{ml}), \mathrm{or} \mathrm{TNF}-\alpha(20 \mathrm{ng} / \mathrm{ml})+$ mangiferin $(500 \mu \mathrm{M} / \mathrm{ml})$. The expression levels of (a) aggrecan, (b) Col-2, (c) MMP-13, and (d) ADAMTS-5 were measured using realtime PCR. (e-i) Levels of the aggrecan, Col-2, MMP-13, and ADAMTS-5 protein were assayed using Western blotting. ( $\mathrm{j}-\mathrm{m}$ ) The expression levels of MMP-13 and Col-2 were detected using IF staining. Scale bar: $100 \mu \mathrm{m}$. All the experiments were repeated at least three times. Significant differences are indicated as follows: ns $P>0.05,{ }^{*} P<0.05,{ }^{* *} P<0.01,{ }^{* * *} P<0.001$, and ${ }^{* * * *} P<0.0001$.

TNF- $\alpha \quad(20 \mathrm{ng} / \mathrm{ml}), \quad$ TNF $-\alpha(20 \mathrm{ng} / \mathrm{ml})+$ mangiferin $(100 \mu$ $\mathrm{M} / \mathrm{ml})$, or TNF $-\alpha(20 \mathrm{ng} / \mathrm{ml})+$ mangiferin $(500 \mu \mathrm{M} / \mathrm{ml})$ for 7 days. Total protein was extracted from the cultured mouse IVD tissues for Western blot analysis, as shown in Figures 4(a)-4(e). Compared with the PBS group, the expression levels of COX-2, iNOS, ADAMTS-5, and MMP-13 were increased by $3.06,1.81,1.91$, and 2.01 times in the TNF- $\alpha$ group. After treatment with different concentrations of mangiferin, the expression of COX-2, iNOS, ADAMTS-5, and MMP-13 decreased by $28.22 \%, 18.16 \%, 24.84 \%$, and $18.49 \%$ and $42.47 \%, 46.49 \%, 33.16 \%$, and 29.61 , respectively. As shown in Figures 4(g)-4(j), the expression of aggrecan and Col-2 was decreased in TNF- $\alpha$-stimulated IVDs compared with IVDs treated with PBS alone. After treatment with two different concentrations of mangiferin, the levels of these inflammatory cytokines decreased in a dose-dependent pattern, and mangiferin mitigated the TNF- $\alpha$-induced loss of aggrecan and Col2. Safranin O staining is a method used to detect proteoglycans and glycosaminoglycans. We used Safranin O staining to evaluate the degree of IVDD in mice and verify the role of mangiferin in inhibiting IVDD. As shown in Figure 4(f), proteoglycans were decreased in the TNF- $\alpha$ group compared with the control group. After treatment with different concentrations of mangiferin, the proteoglycans in the IVD group were gradually increased compared with the TNF- $\alpha$ group. In Figures $4(\mathrm{k})-4(\mathrm{n})$, we used IF staining to determine the expression of COX-2 and MMP-13 in mouse IVD tissues and found that, compared with the PBS group, the expression of COX-2 and MMP-13 increased by 4.21 and 3.14 times in the TNF- $\alpha$ group. Compared with TNF- $\alpha$ group, the expression of MMP-13 and COX-2 decreased by $49.46 \%$ and $48.04 \%$ and $66.68 \%$ and $74.61 \%$, respectively, after treatment with different concentrations of mangiferin. As illustrated in Figures 4(o)$4(\mathrm{r})$, we detected the expression of apoptotic proteins using Western blotting. Compared with the PBS group, the protein levels of the Bax and c-caspase- 3 were increased by 1.67 and 1.38 times and the protein level of $\mathrm{Bcl}-2$ was decreased by $49.48 \%$ in the TNF- $\alpha$ group. After treatment with $100 \mu \mathrm{M} / \mathrm{ml}$ and $500 \mu \mathrm{M} / \mathrm{ml}$ mangiferin, the level of Bcl-2 was increased by 1.41 and 1.74 times, and the levels of Bax and c-caspase- 3 were decreased by $25.33 \%$ and $33.63 \%$ and $22.92 \%$ and 27.80 , respectively. As illustrated in Figures 4(s) and 4(t), TUNELpositive cells were detected in mouse IVD tissues to further verify the role of mangiferin in inhibiting HNPC apoptosis. Compared with that in the PBS group, a greater number of TUNEL-positive cells were observed in the TNF- $\alpha$ group, and the number of TUNEL-positive cells gradually decreased in response to the mangiferin treatment. Based on these results, mangiferin might protect against IVDD by reducing the apoptosis of HNPCs.

3.5. Mangiferin Alleviated the Degeneration of IVD in Rats In Vivo. We established a rat IVD needle puncture model and injected mangiferin into the rat IVD to verify that mangiferin inhibits IVDD in rats. As shown in Figures 5(a) and 5(b), the IVD height was diminished after needle puncture, while mangiferin treatment largely attenuated this degeneration change of IVD, as assayed using X-ray measurements. As shown in Figures 5(c) and 5(d), MRI-T2WI detected a higher signal intensity in the rat IVD after mangiferin treatment than in the IVD of the needle puncture group, which proved that mangiferin plays an active role in the process of IVDD. As illustrated in Figures 5(e) and 5(f), HE staining revealed that mangiferin alleviated the decrease in the height of the intervertebral space associated with IVDD and improved the IVD morphology compared with the needle puncture group. Safranin O staining showed that mangiferin reduced the loss of proteoglycans during the process of IVDD. As shown in Figures 5(g)-5(i), the IHC results showed that injection of mangiferin alleviated the loss of Col-2 and reduced the production of MMP-13 associated with IVDD, which further validated the protective effect of mangiferin on IVDD.

3.6. Mangiferin Antagonized the Activation of the NF- $\kappa B$ Signaling Pathway. Activation of the NF- $\kappa \mathrm{B}$ signaling pathway is known to play an important role in the development of IVDD. We stimulated HNPCs with PBS, TNF- $\alpha$ $(20 \mathrm{ng} / \mathrm{ml}), \quad \mathrm{TNF}-\alpha(20 \mathrm{ng} / \mathrm{ml})+$ mangiferin $(100 \mu \mathrm{M} / \mathrm{ml})$, 

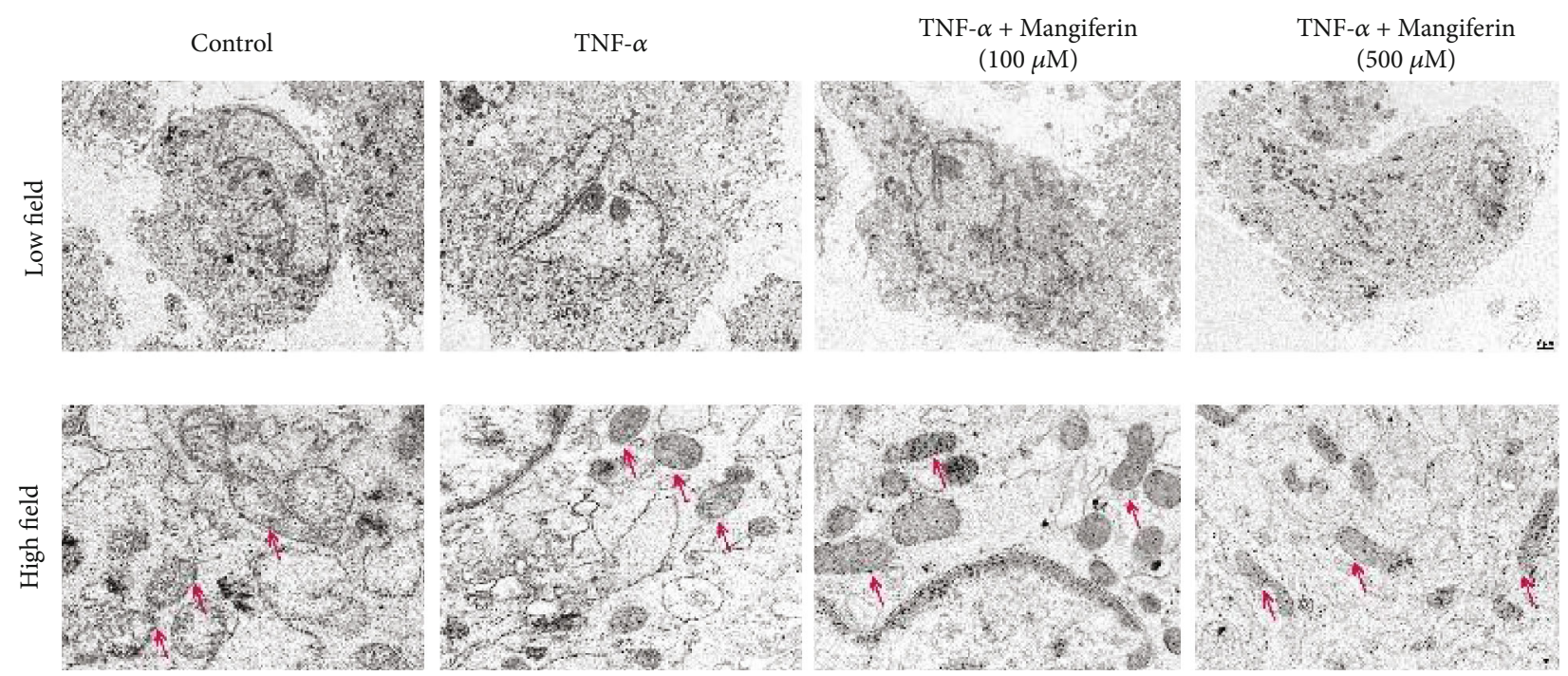

(a)
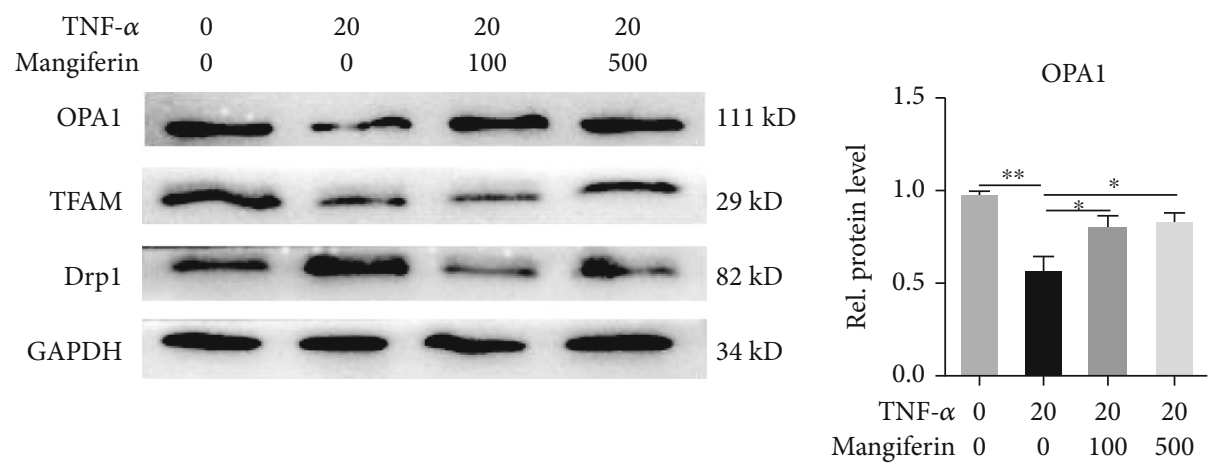

(b)

(c)

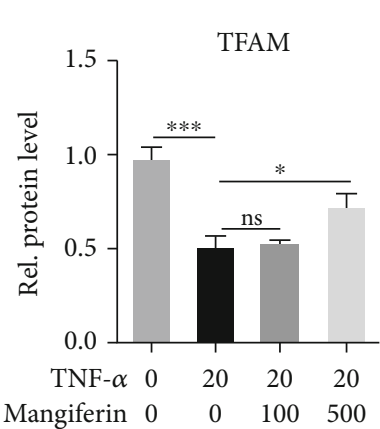

(d)

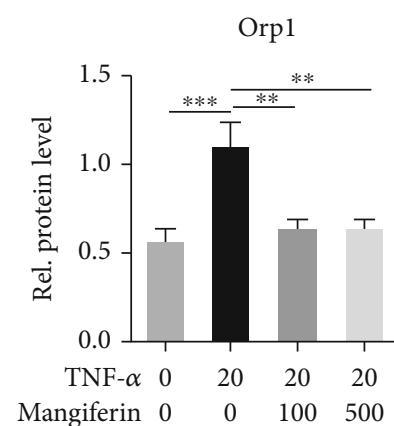

(e)

FIgURe 3: Continued. 


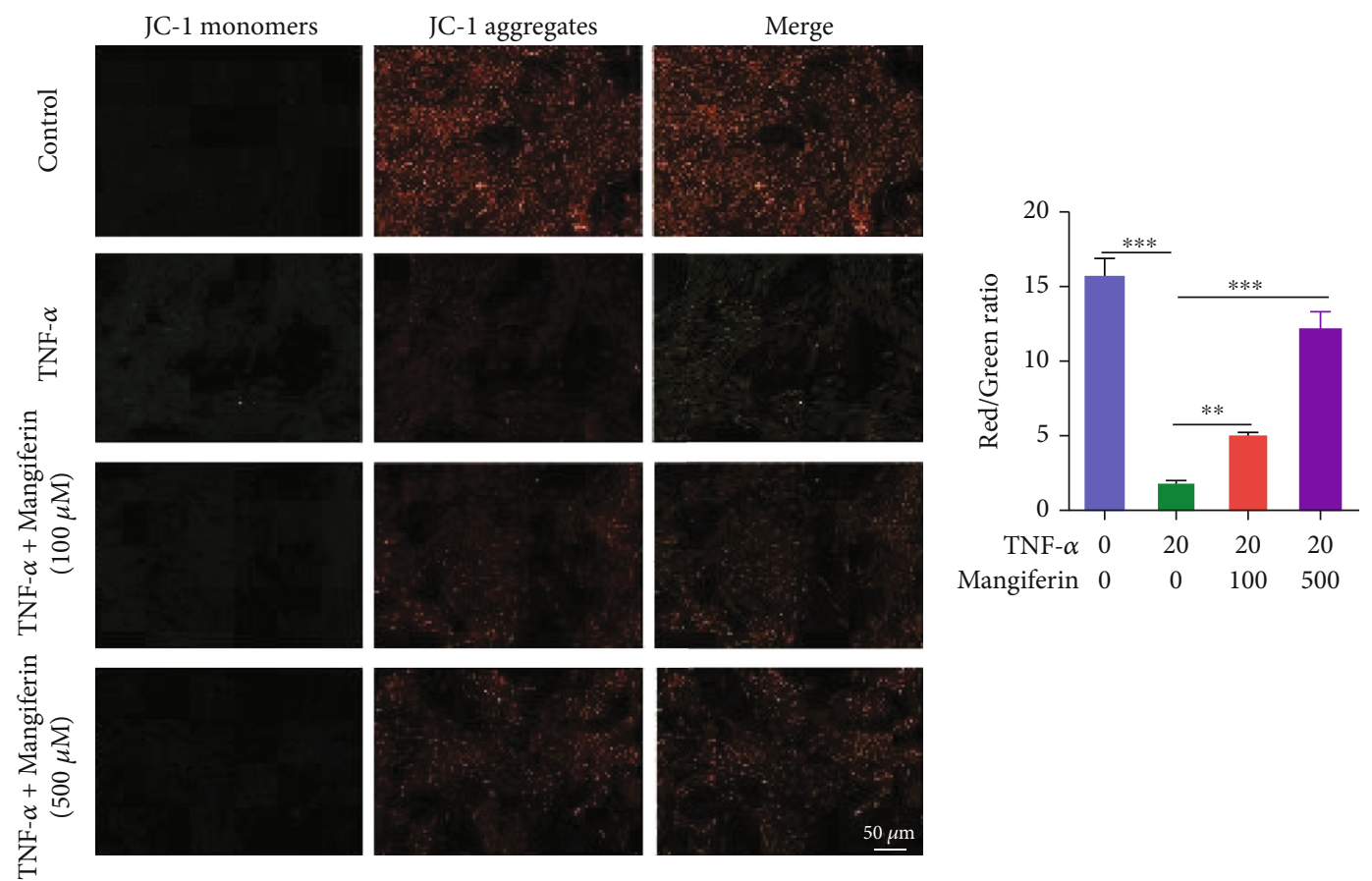

(f)

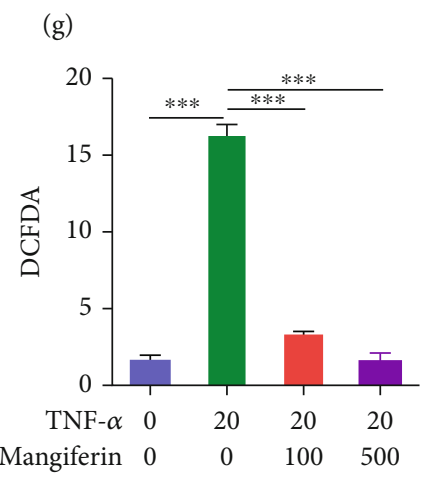

(h)

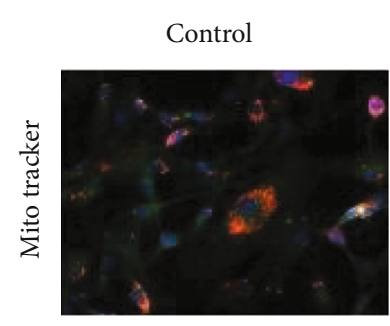

TNF- $\alpha+$ Mangiferin $(100 \mu \mathrm{M})$

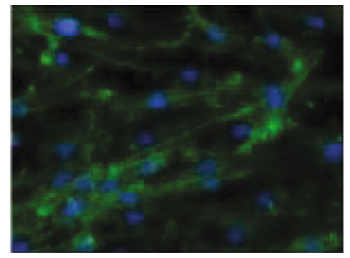

TNF- $\alpha+$ Mangiferin $(500 \mu \mathrm{M})$
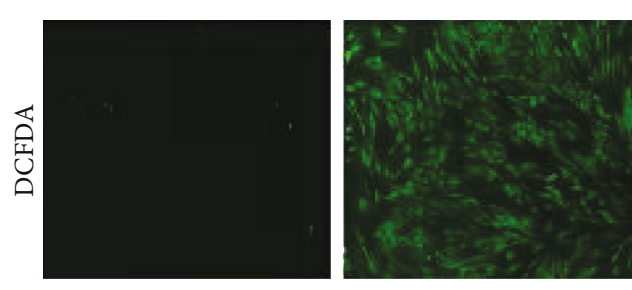

$(100 \mu \mathrm{M})$
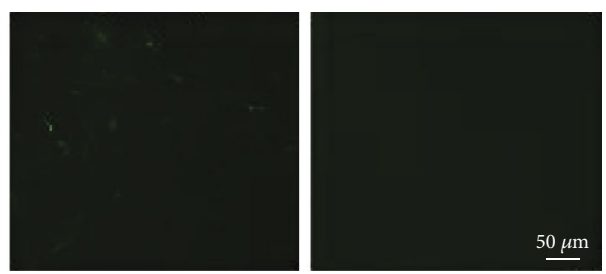

(i)

TNF- $\alpha+$ Mangiferin $(500 \mu \mathrm{M})$

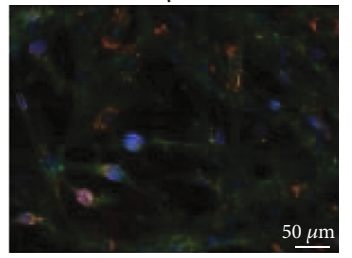

(j)

Figure 3: Continued. 


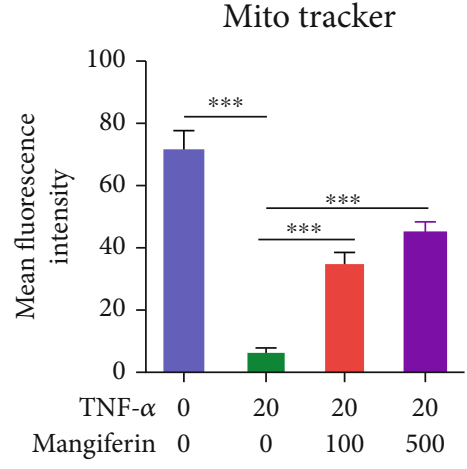

(k)

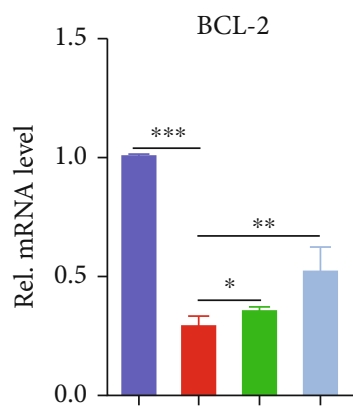

TNF- $\alpha \quad 0 \quad 20 \quad 20 \quad 20$

$\begin{array}{llll}\text { Mangiferin } 0 & 0 & 100 & 500\end{array}$

(m)

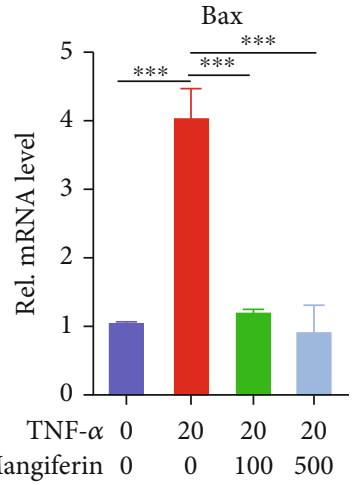

(l)

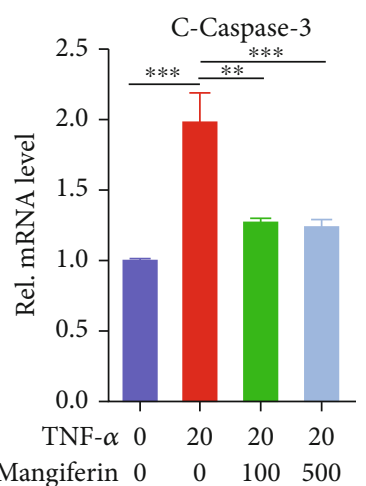

(n)
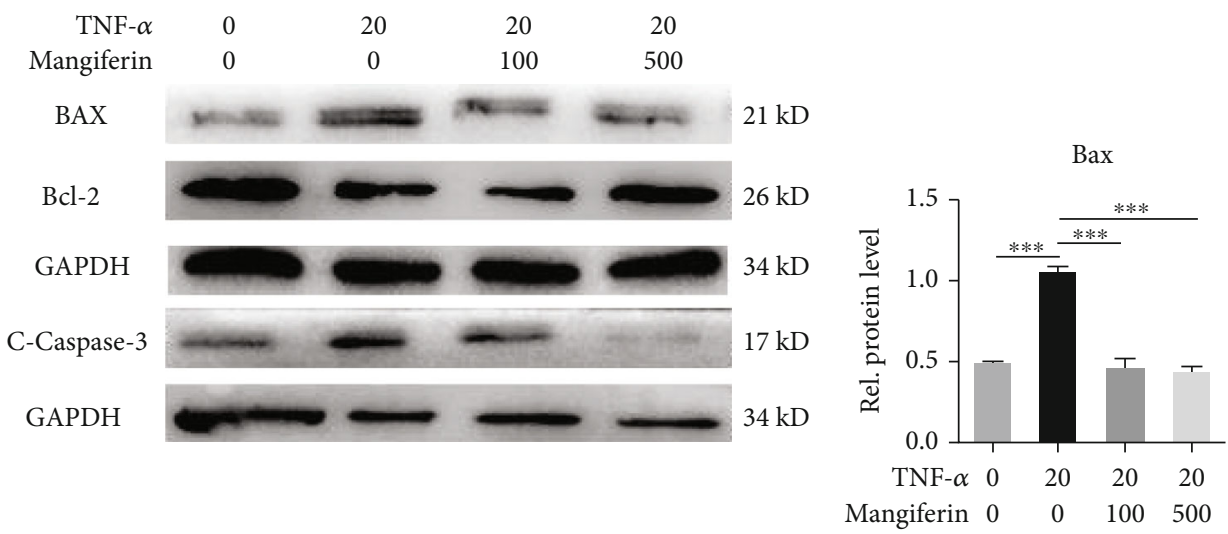

(o)

(p)

BCL-2

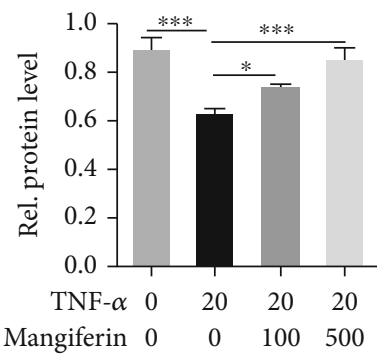

(q)
C-Caspase-3

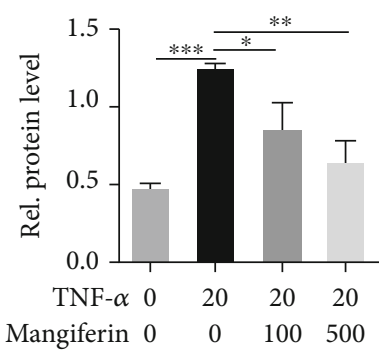

(r)

Figure 3: Continued. 


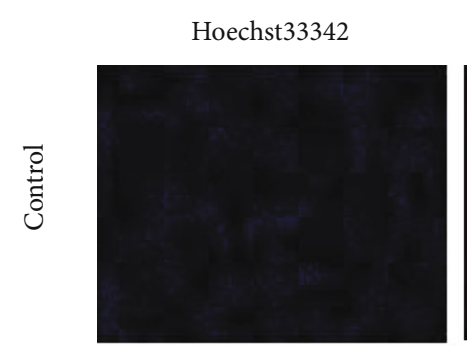

PI
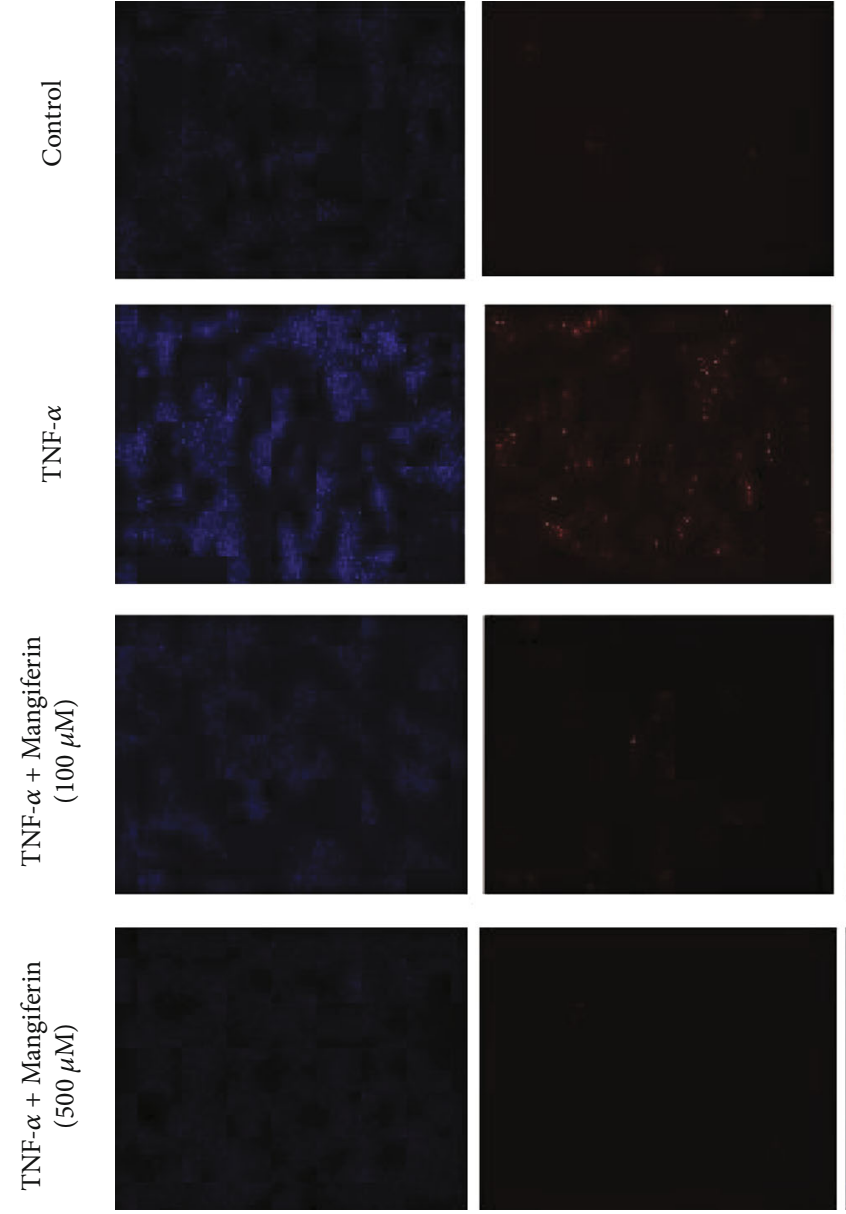

Merge
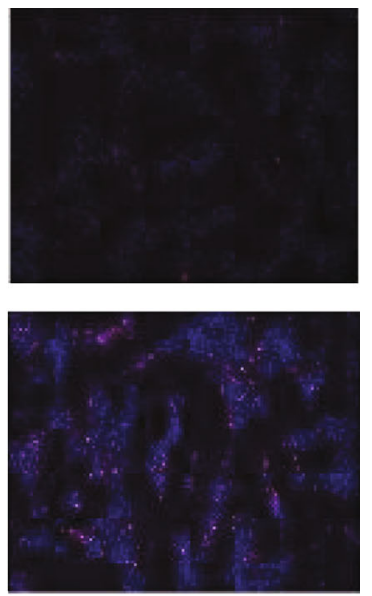

$50 \mu \mathrm{m}$

(s)

Figure 3: Continued. 

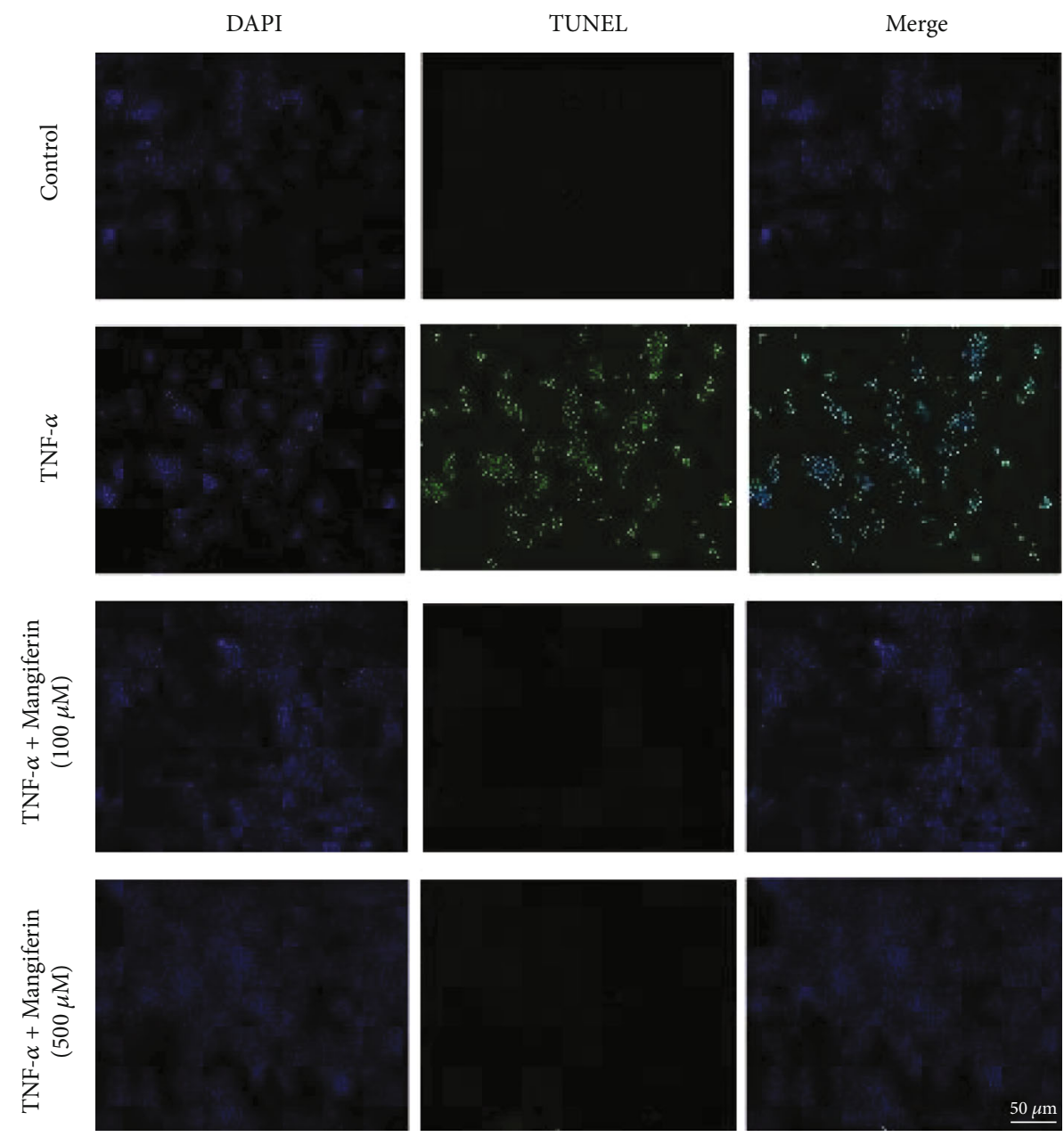

$(\mathrm{t})$

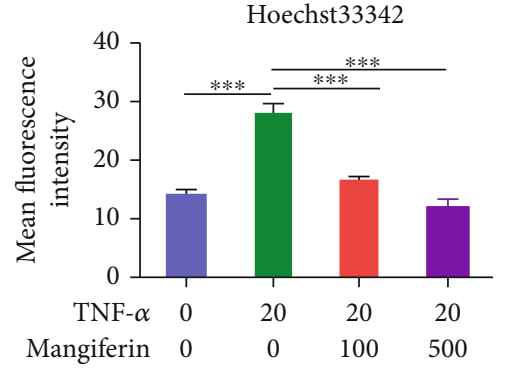

(u)

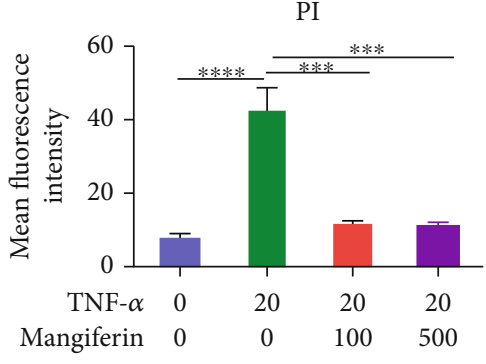

(v)

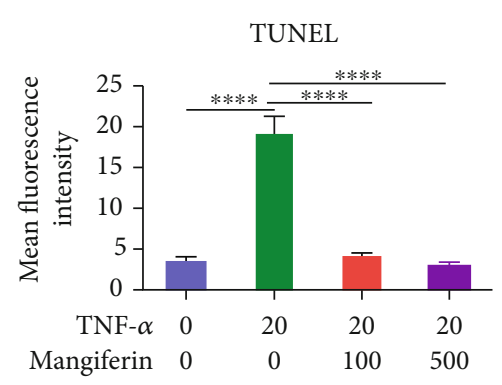

(w)

FiguRE 3: Mangiferin alleviated TNF- $\alpha$-induced mitochondrial dysfunction, oxidative stress, and apoptosis in HNPCs. HNPCs were treated with TNF- $\alpha(20 \mathrm{ng} / \mathrm{ml})$ and different concentrations of mangiferin $(100 \mu \mathrm{M} / \mathrm{ml}$ and $500 \mu \mathrm{M} / \mathrm{ml})$. (a) The mitochondrial morphology in HNPCs was observed using TEM. Scale bars: $5 \mu \mathrm{m}$ and $1 \mu \mathrm{m}$. (b-e) The levels of OPA1, TFAM, and Drp1 were assayed using Western blotting. (f, g) JC-1 was used to detect the mitochondrial membrane potential in HNPCs. Scale bar: $100 \mu \mathrm{m}$. (h, i) ROS levels were detected in HNPCs from each treatment group. Scale bar: $100 \mu \mathrm{m} .(\mathrm{j}, \mathrm{k})$ MitoTracker was used to detect the mitochondrial membrane potential of HNPCs. Scale bar: $25 \mu \mathrm{m}$. The expression of (l) Bax, (m) Bcl-2, and (n) c-caspase-3 in each indicated group was assayed using real-time PCR. (o-r) The levels of Bax, Bcl-2, and c-caspase-3 were assayed using Western blotting. (s, u, v) Hoechst 33342 and (t, w) TUNEL staining of the HNPCs in each indicated group. Scale bar: $100 \mu \mathrm{m}$. All the experiments were repeated at least three times. Significant differences are indicated as follows: ns $P>0.05,{ }^{*} P<0.05,{ }^{* *} P<0.01,{ }^{* * *} P<0.001$, and ${ }^{* * * *} P<0.0001$.

and $\mathrm{TNF}-\alpha(20 \mathrm{ng} / \mathrm{ml})+$ mangiferin $(500 \mu \mathrm{M} / \mathrm{ml})$ for $1 \mathrm{~h}$ and extracted total mRNA and total protein for analysis to explore whether mangiferin protects against IVDD by inhibiting the NF- $\kappa \mathrm{B}$ signaling pathway. Notably, $\mathrm{pI} \kappa \mathrm{B} \alpha$ and p65 are important parameters used to measure the activation of the NF- $\kappa \mathrm{B}$ signaling pathway [34]. As shown in Figure 6(a), compared with the PBS group, the expression level of NF- $\kappa B_{1}$ increased 1.70 times after stimulation with 


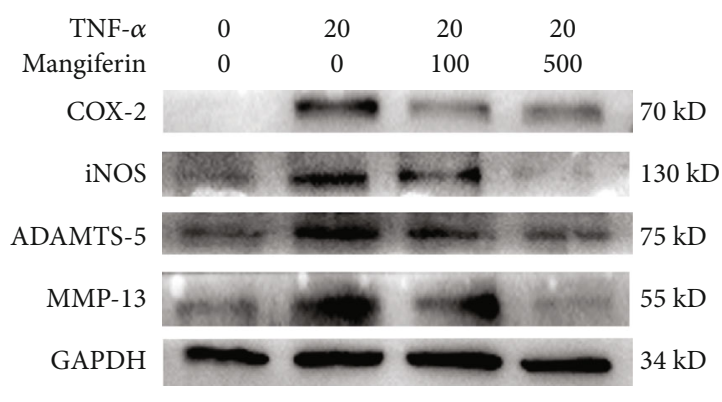

(a)

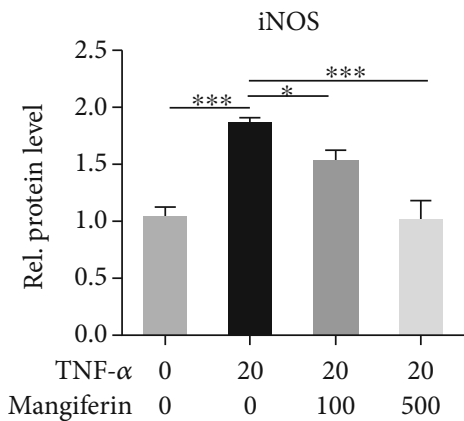

(c)

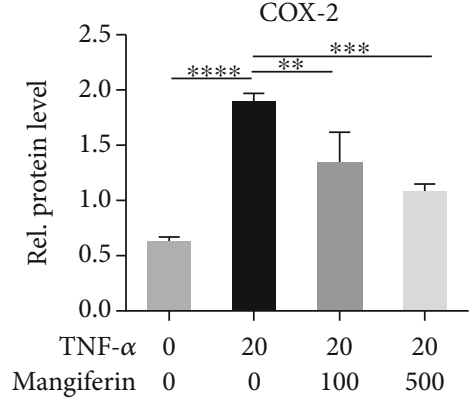

(b)

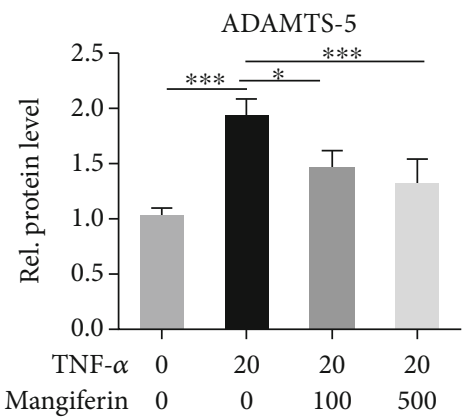

(d)
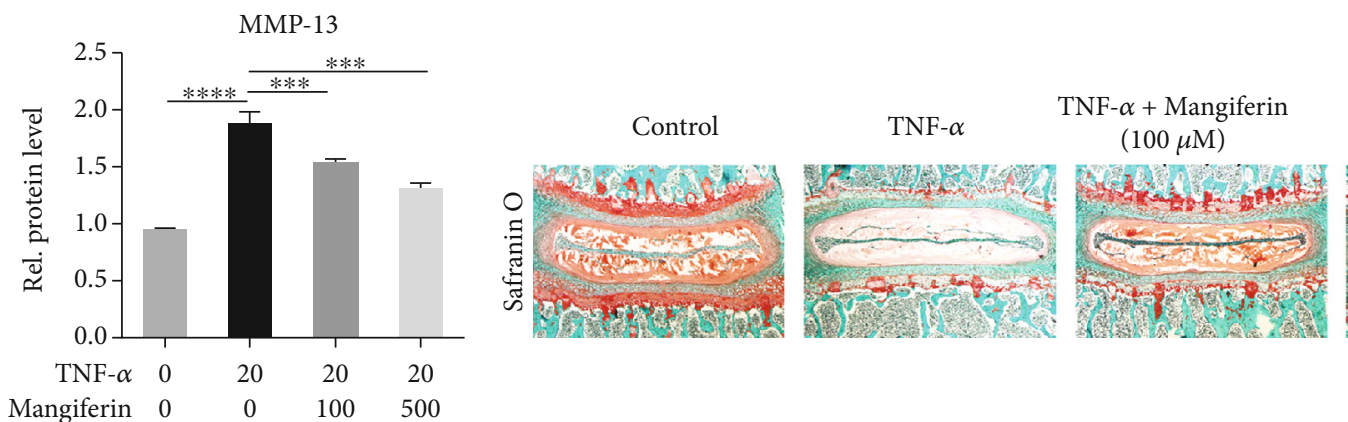

TNF- $\alpha+$ Mangiferin $(500 \mu \mathrm{M})$

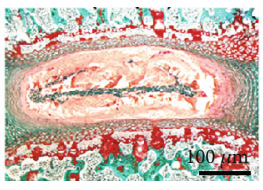

(e)
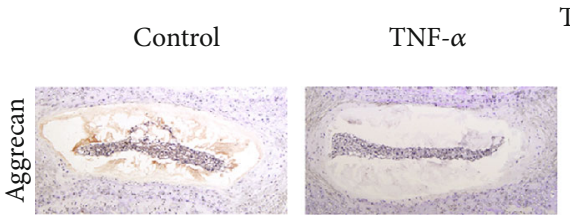

TNF- $\alpha+$ Mangiferin $(100 \mu \mathrm{M})$

TNF- $\alpha+$ Mangiferin

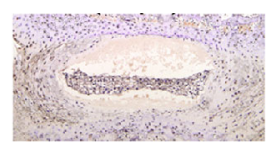
$(500 \mu \mathrm{M})$

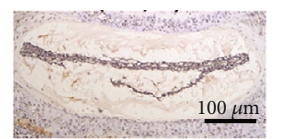

(g)

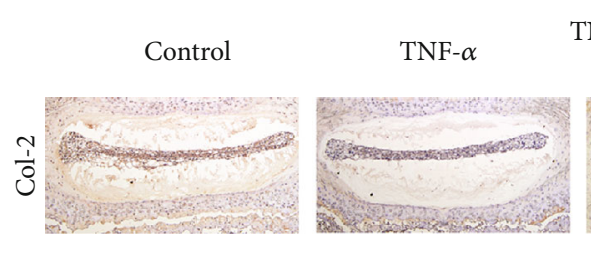

TNF- $\alpha+$ Mangiferin $(100 \mu \mathrm{M})$

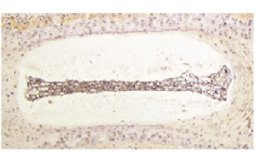

(h)

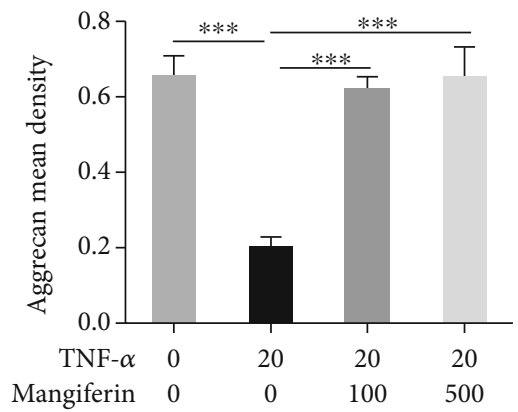

(i)

Figure 4: Continued. 


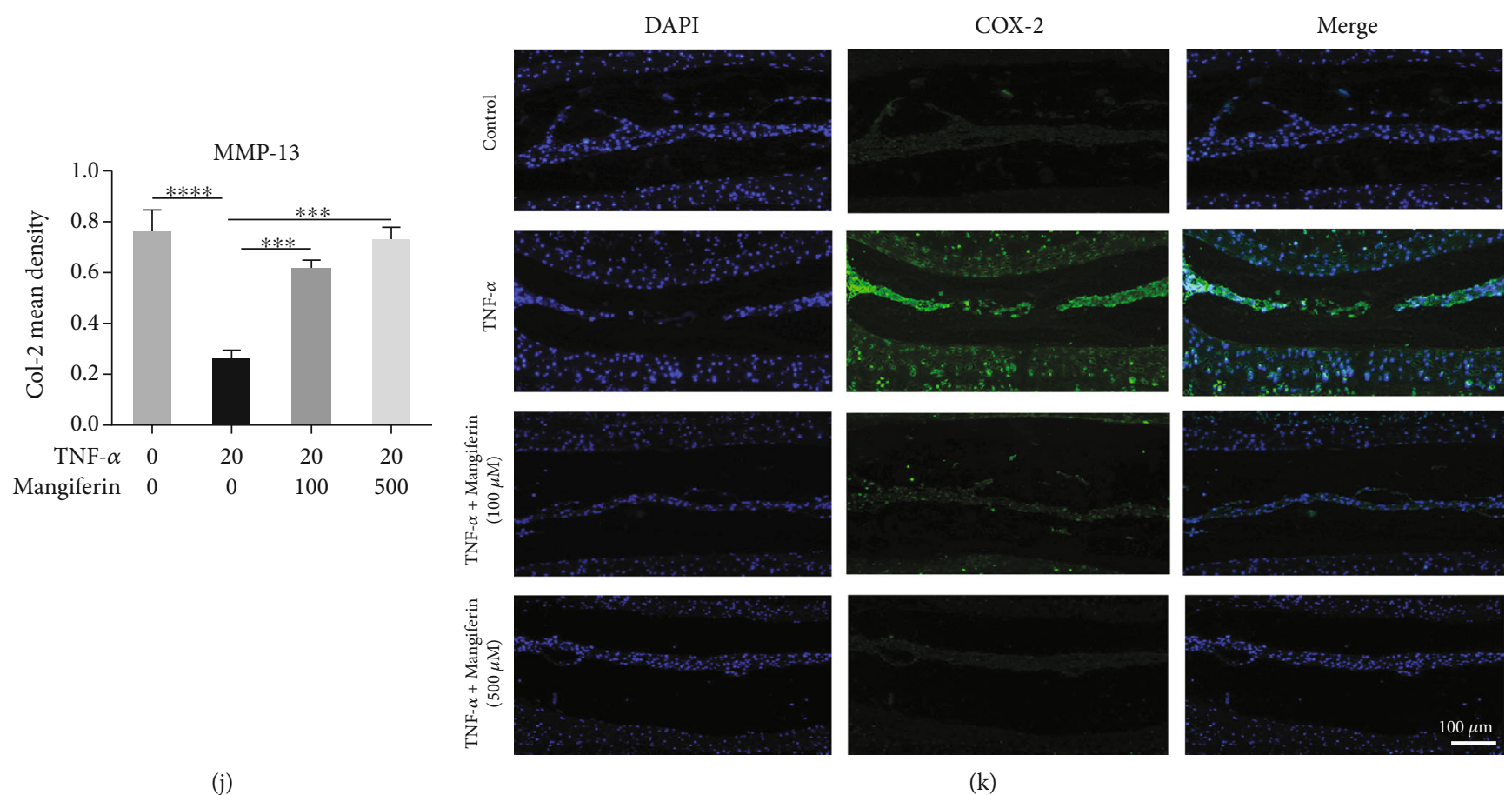

COX-2

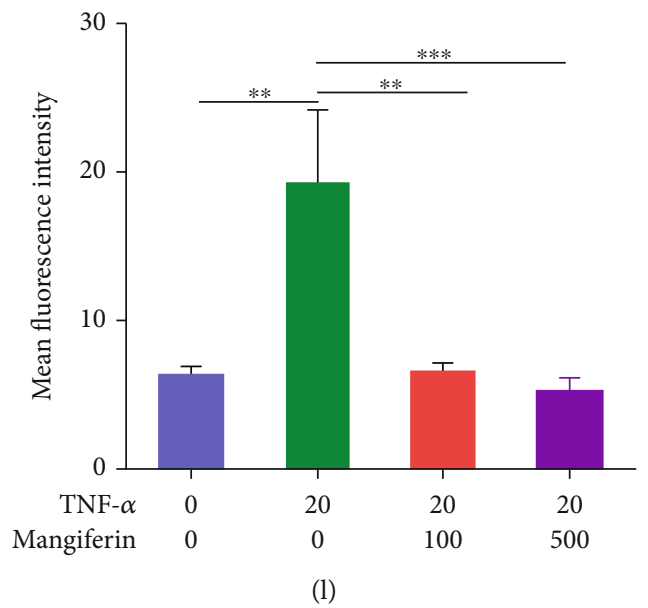

Figure 4: Continued. 


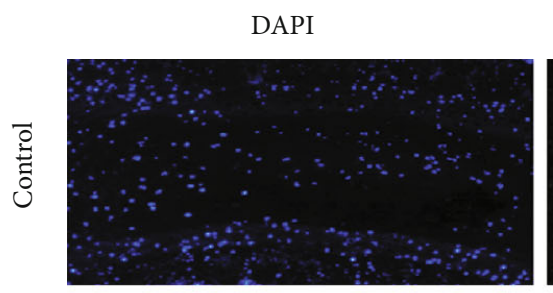

MMP-13
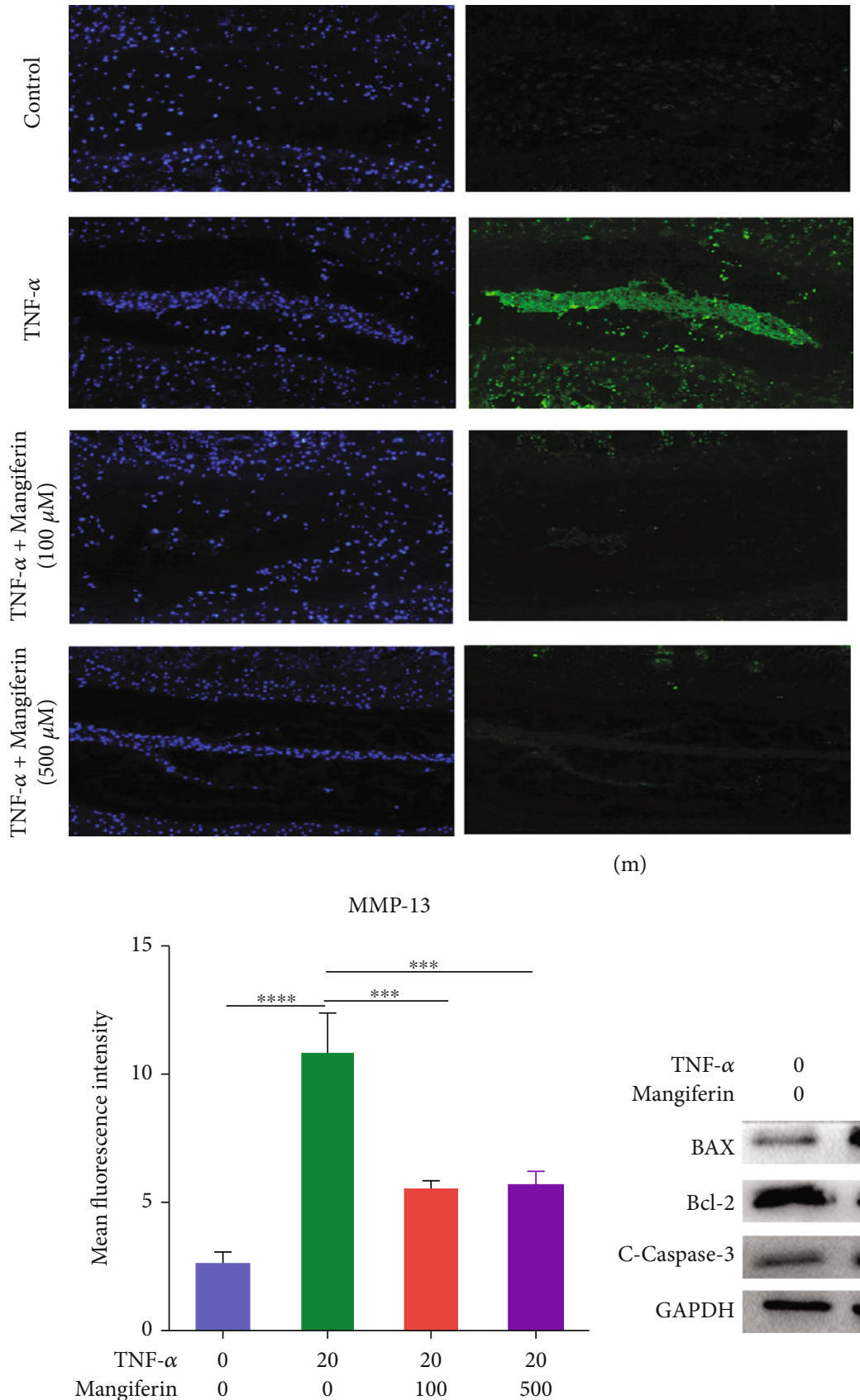

(n)
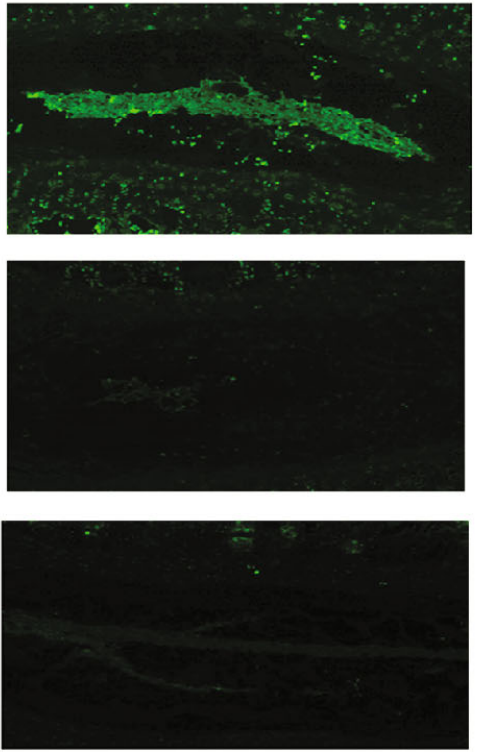

(m)
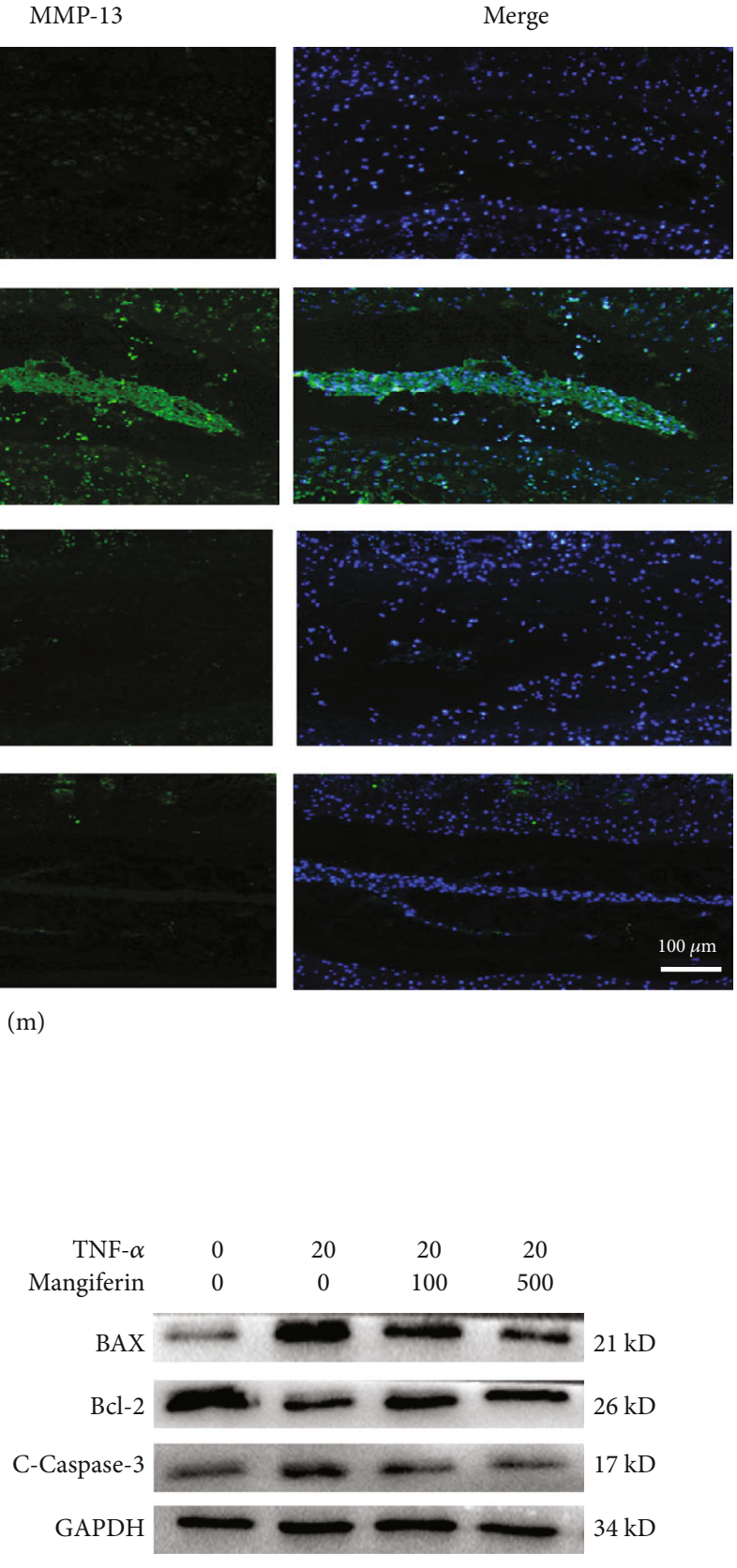

Figure 4: Continued. 


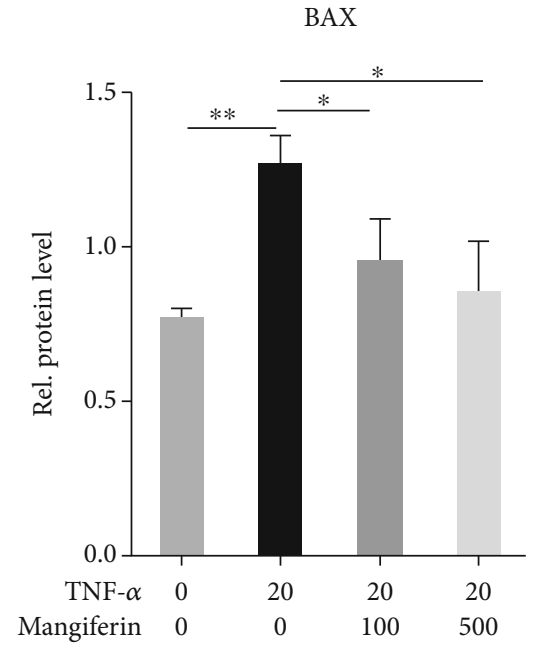

(p)
Bcl-2

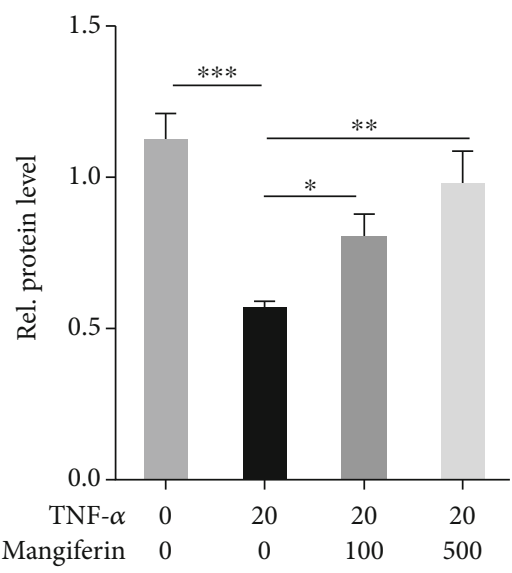

(q)

C-Caspase-3

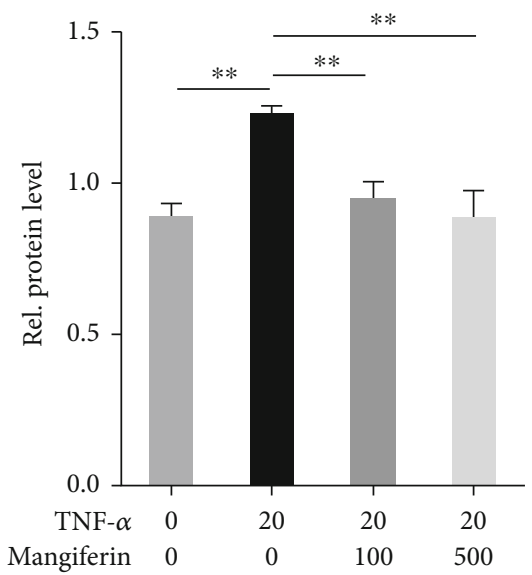

(r)

Figure 4: Continued. 

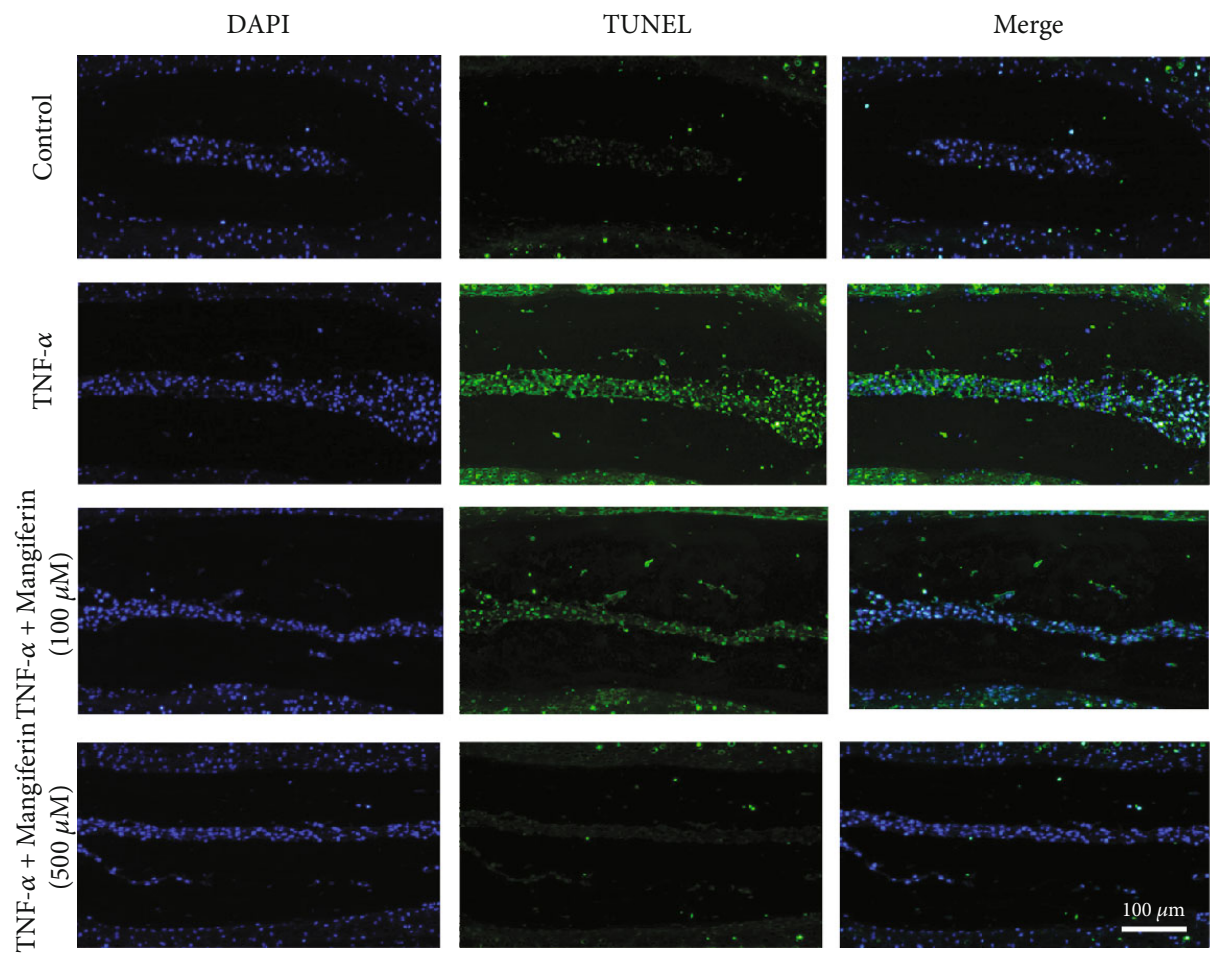

(s)

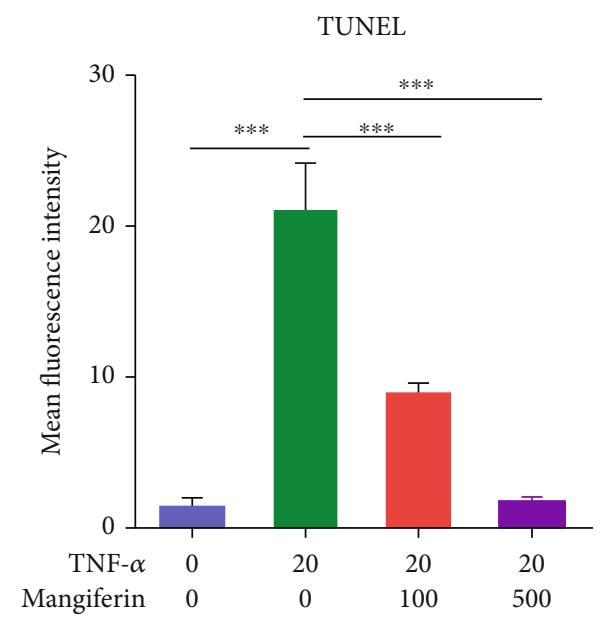

(t)

FIGURE 4: Mangiferin alleviated the pathological reactions associated with IVDD caused by TNF- $\alpha$ in cultured mouse IVD tissues. The IVD tissues from mice were treated with PBS $(n=7)$ or TNF- $\alpha(20 \mathrm{ng} / \mathrm{ml}, n=7)$ in the presence or absence of mangiferin $(100 \mu \mathrm{M} / \mathrm{ml}, n=7$; $500 \mu \mathrm{M} / \mathrm{ml}, n=7$ ). (a-e) Total protein was extracted, and levels of the COX-2, iNOS, ADAMTS-5, and MMP-13 proteins were evaluated using Western blotting. (f) Safranin O staining was performed after treating the mouse IVD tissues with TNF- $\alpha$ and different concentrations of mangiferin. Scale bar: $100 \mu \mathrm{m}$. (g, i) The expression level of aggrecan in mouse IVD tissues was detected using IHC staining. Scale bar: $100 \mu \mathrm{m}$. (h, j) IHC staining showing the level of Col-2 in mouse IVD tissues. Scale bar: $100 \mu \mathrm{m}$. (k-n) We detected the expression levels of COX-2 and MMP-13 using IF staining. Scale bar: $100 \mu \mathrm{m}$. (o-r) We detected the expression levels of Bax, Bcl-2, and c-caspase-3 using Western blotting. (s, t) TUNEL staining of the IVD tissues from mice in each indicated group. Scale bar: $100 \mu \mathrm{m}$. All the experiments were repeated at least three times. Significant differences are indicated as follows: ${ }^{*} P<0.05,{ }^{* *} P<0.01,{ }^{* * *} P<0.001$, and ${ }_{* * * *} P<0.0001$.

TNF- $\alpha$ for $1 \mathrm{~h}$, whereas the expression level of NF- $\kappa \mathrm{B}_{1}$ decreased by $42.15 \%$ and $51.12 \%$ after treatment with different concentrations of mangiferin. As shown in Figures 6(b)6(d), compared with the PBS group, the protein levels of the $\mathrm{pI} \kappa \mathrm{B} \alpha / \mathrm{I} \kappa \mathrm{B} \alpha$ and $\mathrm{pp} 65 / \mathrm{P} 65$ increased after treatment with
TNF- $\alpha$, whereas their levels were decreased after treatment with different concentrations of mangiferin. In addition, the IF staining shown in Figures 6(e) and 6(g) indicated that the TNF- $\alpha$-induced increase in the level of pp65 was abolished by treatment with mangiferin. As shown in 


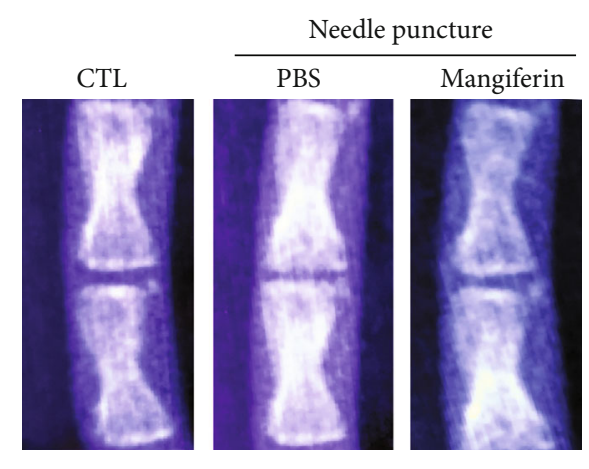

(a)

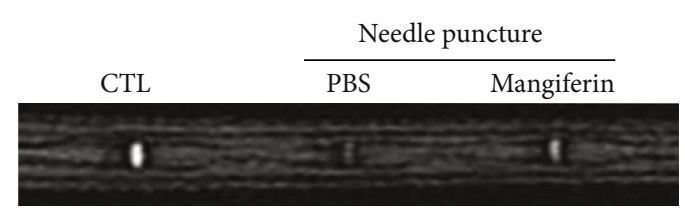

(c)
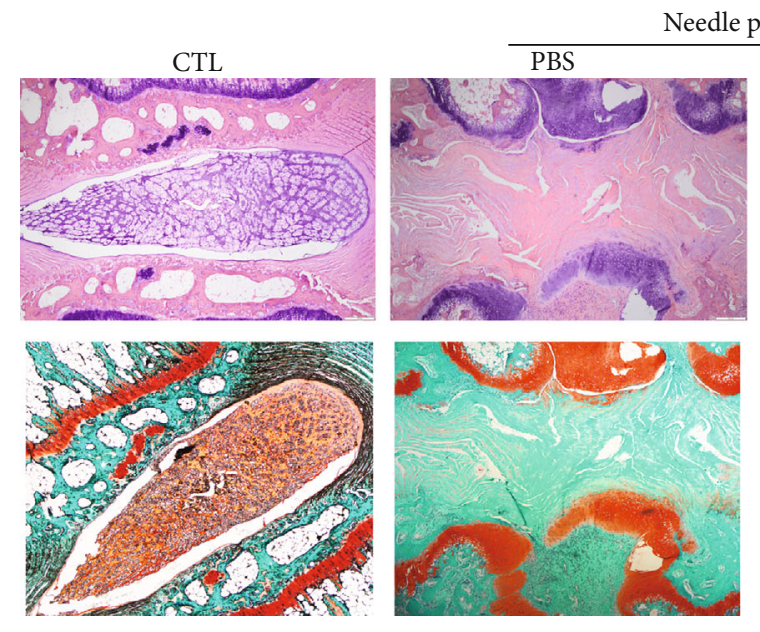

(e)

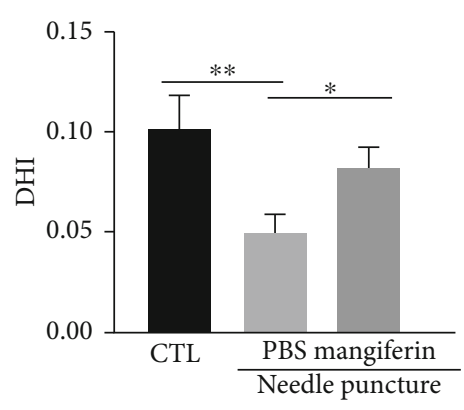

(b)

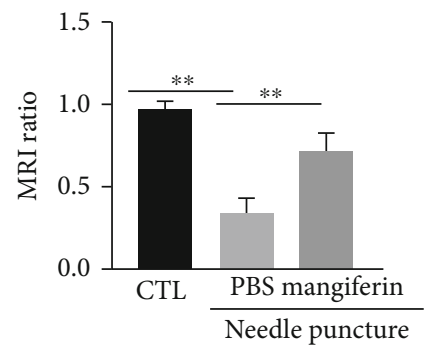

(d)

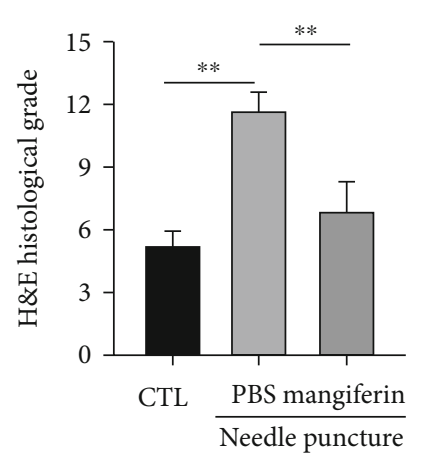

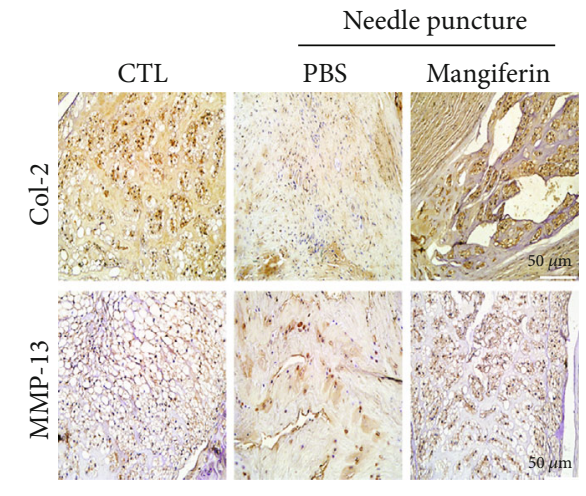

(g)

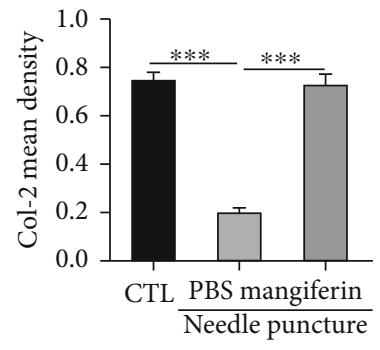

(h)

Figure 5: Continued. 


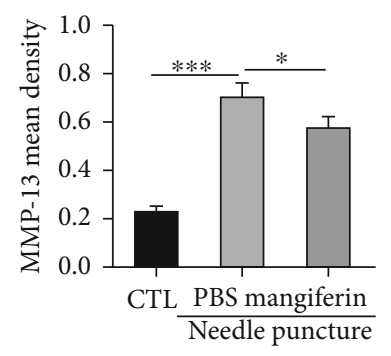

(i)

FIgURE 5: Mangiferin alleviated the degeneration of the rat IVD in vivo. (a, b) X-ray was obtained to measure the height of the intervertebral space in rats from each group $(n=5)$. (c, d) MRI was used to assess the degree of IVDD in rats from each group $(n=5)$. (e, f) HE and SO staining were performed to analyze the IVDs in rats from each group $(n=5)$. Scale bar: $100 \mu \mathrm{m}$. (g-i) IHC was used to measure the expression of Col-2 and MMP-13 in each group $(n=5)$. All the experiments were repeated at least three times. Scale bar: $50 \mu \mathrm{m}$. Significant differences are indicated as follows: ${ }^{*} P<0.05,{ }^{* *} P<0.01,{ }^{* * *} P<0.001$, and ${ }^{* * * *} P<0.0001$.

Figures 6(f) and 6(h), HNPCs were collected and IF staining showed that different concentrations of mangiferin could eliminate TNF- $\alpha$-induced p65 nuclear translocation.

\section{Discussion}

Previous studies have confirmed that IVDD is mediated by the abnormal production of proinflammatory molecules secreted by various cell types [35-37]; various proinflammatory cytokines and chemokines are reported to be associated with IVDD [38-41], among which TNF- $\alpha$ has been widely studied and shown to facilitate the development of IVDD. As mentioned above, TNF- $\alpha$ promotes the production of various inflammatory cytokines and causes ECM degradation, leading to increased catabolism of the IVD [42]; therefore, it is a promising target for the treatment of clinical IVDD. In our study, we established a TNF- $\alpha$-induced inflammatory response model of HNPCs to explore the role of mangiferin in inhibiting IVDD and to investigate the mechanism of this effect. The expression levels of COX-2 and iNOS secreted by HNPCs were significantly elevated after treatment with TNF$\alpha$ compared with those in the PBS group; consistent with previous studies, it was demonstrated that TNF- $\alpha$ caused the inflammatory response of HNPCs and resulted in the production of important inflammatory cytokines that contribute to IVDD. Intriguingly, after treatment with mangiferin, the expression of these inflammatory cytokines decreased compared with the TNF- $\alpha$ group. Furthermore, TNF- $\alpha$ increased the expression of MMPs and ADAMTSs, which leads to the destruction of the ECM, an important aspect of the pathological process of IVDD $[29,43]$. In our study, TNF- $\alpha$ markedly increased the expression of MMP-13 and ADAMTS-5, leading to a significant decrease in aggrecan and Col-2 expression, which are the main components of the IVD, implying a certain level of anabolism [40]. Previous studies have shown that mangiferin alleviates Col-2 and aggrecan loss in tert-butyl hydroperoxide-stimulated chondrocytes [20]. In our vivo and vitro experiments, TNF- $\alpha$ enhanced the expression level of the catabolic markers MMP-13 and ADAMTS-5 and diminished the expression levels of the anabolic markers aggrecan and Col-2 compared with the control group. The addition of mangiferin at different concentrations alleviated the loss of Col-2 and aggrecan induced by TNF- $\alpha$ and decreased the expression of MMP-13 and ADAMTS-5, indicating that mangiferin might protect against disorganization of anabolism in IVDD.

Previous studies reported the abnormal morphology and dysfunction of mitochondria in aging NP cells [27], and mitochondrial dysfunction plays an important role in promoting the development of IVDD. In our study, compared with the control group, the mitochondria of HNPCs were swollen and deformed after TNF- $\alpha$ treatment, and the expression level of ROS was increased, which in turn led to inflammatory response of HNPCs and the damage of mitochondrial function, and mangiferin reduced these changes in mitochondria and ROS production. Moreover, mangiferin plays a protective role in mitochondrial function by affecting the expression of mitochondrial morphology and functionrelated indicators, thereby mitigating the process of IVDD by reducing mitochondrial dysfunction and ROS production. Apoptosis causes a significant decrease in the number of living and functional IVD cells, which results in increased expression of proinflammatory cytokines and exacerbates IVDD [8]. A large number of studies have shown that TNF- $\alpha$ induces the apoptosis of NP cells, which significantly increases the apoptotic rate and senescence $[14,44,45]$. The imbalance of Bax and Bcl-2 expression is involved in the mitochondrial apoptosis pathway during IVD degeneration, inducing the expression of c-caspase- 3 and promoting the apoptosis of NP cells [46]. In our study, after TNF- $\alpha$ stimulation of HNPCs, we observed increased levels of Bax and ccaspase- 3 and decreased levels of Bcl-2, and these results suggest that TNF- $\alpha$ could increase the expression of proapoptotic parameters and reduce the expression of antiapoptotic parameters and may be involved in mitochondrial apoptosis pathway. After treatment with mangiferin, the levels of Bax and c-caspase- 3 decreased, and the expression of Bcl-2 increased. These results imply that mangiferin reduces the TNF- $\alpha$-induced increase in the apoptosis rate of HNPCs, thus plays a role in relieving IVDD. To further validate our study, we further observed the effect of mangiferin on TNF$\alpha$-induced apoptosis of HNPCs by TUNEL and Hoechst 33342 staining. Compared with TNF- $\alpha$ stimulation group, mangiferin can alleviate the expression of inflammatory 


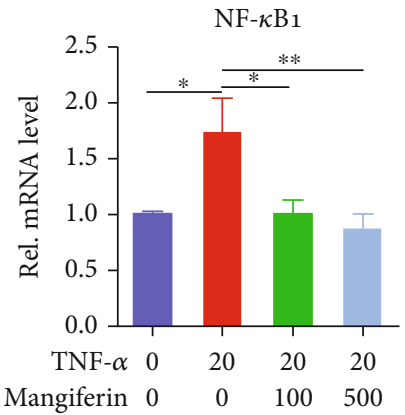

(a)

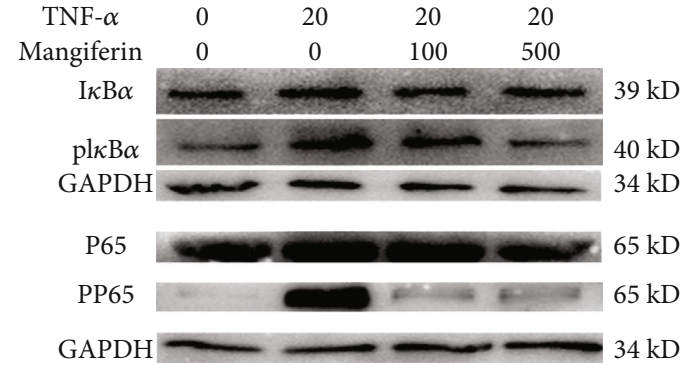

(b)

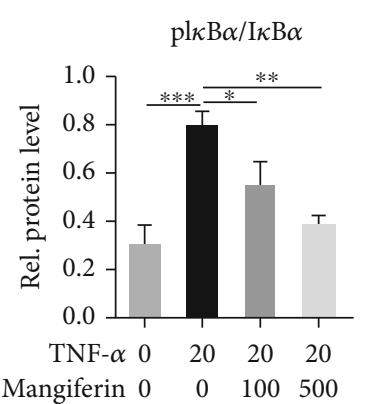

(c)

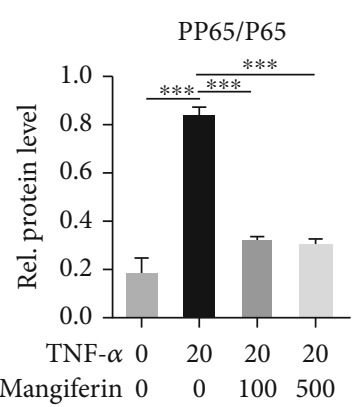

(d)

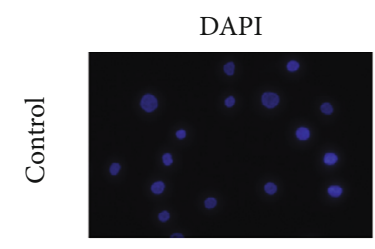

PP65
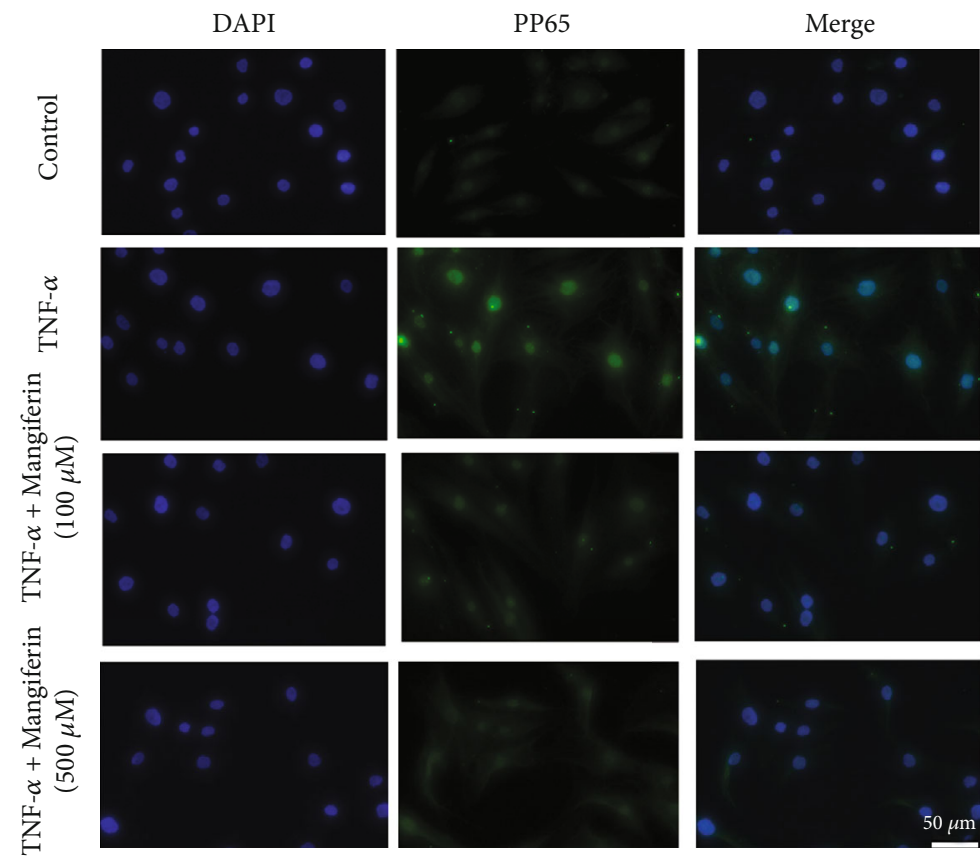

(e)

Figure 6: Continued. 


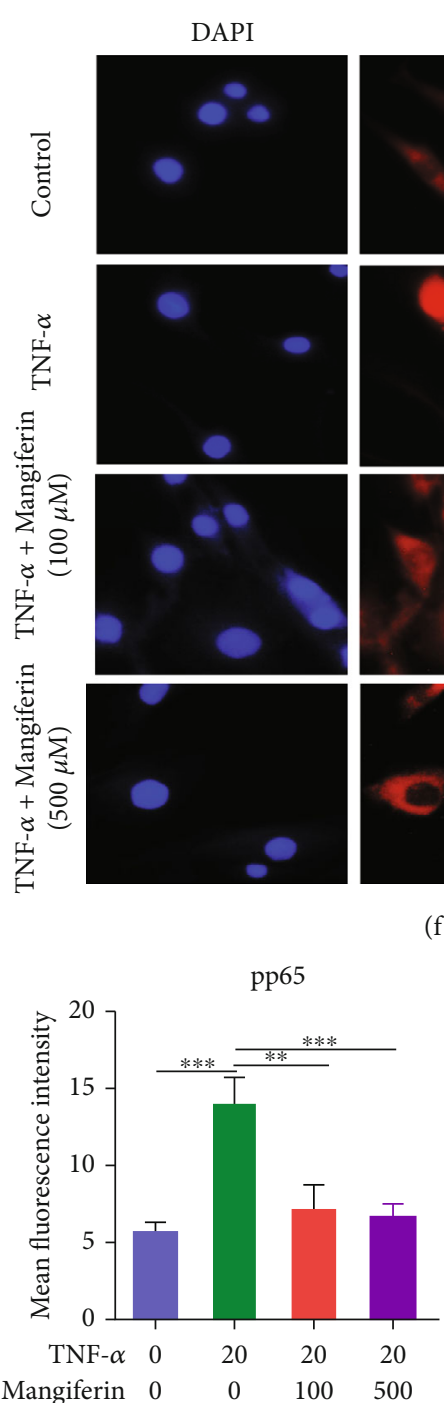

(g)

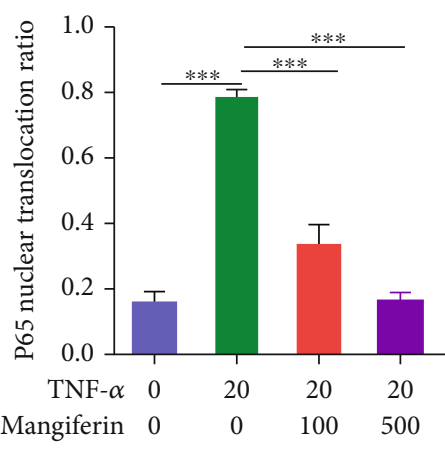

(h)

Figure 6: Mangiferin antagonized the TNF- $\alpha$-induced activation of the NF- $\kappa$ B signaling pathway. HNPCs were treated with PBS, TNF- $\alpha$ $(20 \mathrm{ng} / \mathrm{ml}), \quad \mathrm{TNF}-\alpha(20 \mathrm{ng} / \mathrm{ml})+$ mangiferin $(100 \mu \mathrm{M} / \mathrm{ml})$, or $\mathrm{TNF}-\alpha(20 \mathrm{ng} / \mathrm{ml})+$ mangiferin $(500 \mu \mathrm{M} / \mathrm{ml})$. (a) Total mRNA was extracted, and the expression of NF- $\kappa \mathrm{B}_{1}$ was assayed using real-time PCR. (b-d) Total protein was extracted, and the levels of pI $\kappa \mathrm{B} \alpha$ and pp65 were evaluated using Western blotting. (e, g) Representative images of IF staining for pp65 in cultured HNPCs from each group. Scale bar: $50 \mu \mathrm{m}$. (f, h) Nuclear translocation of NF- $\kappa \mathrm{B}$ p65 in HNPCs as determined through IF staining. Scale bar: $25 \mu \mathrm{m}$. All the experiments were repeated at least three times. Significant differences are indicated as follows: ${ }^{*} P<0.05,{ }^{* *} P<0.01,{ }^{* * *} P<0.001$, and ${ }^{* * * *} P<0.0001$.

cytokines, reduce the loss of Col-2 and aggrecan, and alleviate the apoptosis of IVD in mice. Moreover, in vitro experiments further suggested that mangiferin can alleviate multiple pathological processes in IVDD.

In the in vivo experiment using rats, compared with the needle puncture group, intradiscal injection of mangiferin can alleviate the loss of IVD height and IVD major contents and reduce the expression of inflammatory cytokines. Therefore, the results suggest that mangiferin might play a protective role in IVDD in vivo and in vitro.

In addition, previous studies have reported that activation of the NF- $\kappa \mathrm{B}$ signaling pathway is involved in IVDD, activation of NF- $\kappa \mathrm{B}$ signaling pathway can accelerate IVDD, while antagonism of NF- $\kappa \mathrm{B}$ signaling pathway can alleviate the aging process [24]. TNF- $\alpha$ is involved in various pathological processes related to IVDD, mainly by activating the NF- $\kappa \mathrm{B}$ signaling pathway [26]. The detection of mRNA expression showed that mangiferin inhibited the increase in NF- $\kappa \mathrm{B}_{1}$ expression caused by TNF- $\alpha$. Levels of the pI $\kappa \mathrm{B}$ and pp65 proteins, which are critical parameters for investigating the activity of the NF- $\kappa \mathrm{B}$ signaling pathway [34], also increased after treatment with TNF- $\alpha$. The levels of $\mathrm{pI} \kappa \mathrm{B}$ and pp65 were significantly reduced by mangiferin treatment. In addition, nuclear translocation of $\mathrm{p} 65$ determines the activity of NF- $\kappa$ B signaling pathway [47]. Moreover, after treatment with mangiferin, nuclear translocation of p65 can be inhibited, so it plays an important and positive role in blocking the activation of $\mathrm{NF}-\kappa \mathrm{B}$ signaling pathway. 
In conclusion, mangiferin exerts a positive effect on alleviating IVDD by inhibiting the inflammatory response of HNPCs, increasing the loss of major components that contributes to the progression of IVDD, and preserving mitochondrial function by reducing ROS production, which reduces the expression of apoptosis-related proteins. In our future studies, we expect to develop mangiferin as a clinical treatment for IVDD.

\section{Abbreviations}

IVDD: Intervertebral disc degeneration

HNPCs: Human nucleus pulposus cells

LBP: $\quad$ Low back pain

IVD: Intervertebral disc

ROS: $\quad$ Reactive oxygen species

NP: $\quad$ Nucleus pulposus

Col-2: $\quad$ Type II collagen

ECM: $\quad$ Extracellular matrix

ADAMTSs: A disintegrin and metalloproteinase with thrombospondin motifs

c-caspase-3: Cleaved-caspase-3

TFAM: $\quad$ Mitochondrial transcription factor A

OPA1: $\quad$ Optic Atrophy 1

Drp1: Dynamin-related protein 1

pI $\kappa \mathrm{B} \alpha$ : $\quad$ Phosphorylated $\mathrm{I} \kappa \mathrm{B} \alpha$

pp65: $\quad$ Phosphorylated p65

MRI: $\quad$ Magnetic resonance imaging

IHC: Immunohistochemical

HE: $\quad$ Hematoxylin and eosin

IF: Immunofluorescence

TEM: Transmission electron microscopy.

\section{Data Availability}

The data collected for the study are available from the corresponding author upon request.

\section{Conflicts of Interest}

The authors have no competing interests to declare.

\section{Authors' Contributions}

HCY, YPZ, and LC participated in the study design, data analysis, and manuscript drafting. HCY, GWH, JKC, and YYY participated in the experimental operation. Haichao $\mathrm{Yu}$ is the first author. Yunpeng Zhao and Lei Cheng contributed equally to this work and should be considered as equal corresponding authors. All authors read and approved the final manuscript, and all authors consent to its publication.

\section{Acknowledgments}

The study was supported by grants from the Key Research and Development Program of Shandong Province (grant no. 2019GSF108029), National Key Research and Development Program (grant no. 2020YFC2009004), Shandong Natural Science Foundation (grant no. ZR2020YQ54), and
National Natural Science Foundation of China (grant nos. 81572191 and 82072478).

\section{References}

[1] B. F. Walker, "The prevalence of low back pain: a systematic review of the literature from 1966 to 1998," Journal of Spinal Disorders, vol. 13, no. 3, pp. 205-217, 2000.

[2] P. Cote, J. D. Cassidy, and L. Carroll, "The Saskatchewan Health and Back Pain Survey. The prevalence of neck pain and related disability in Saskatchewan adults," Spine, vol. 23, no. 15, pp. 1689-1698, 1998.

[3] G. Hou, H. Lu, M. Chen, H. Yao, and H. Zhao, "Oxidative stress participates in age-related changes in rat lumbar intervertebral discs," Archives of Gerontology and Geriatrics, vol. 59, no. 3, pp. 665-669, 2014.

[4] S. Suzuki, N. Fujita, N. Hosogane et al., "Excessive reactive oxygen species are therapeutic targets for intervertebral disc degeneration," Arthritis Research \& Therapy, vol. 17, no. 1, p. 316, 2015.

[5] L. Poveda, M. Hottiger, N. Boos, and K. Wuertz, "Peroxynitrite induces gene expression in intervertebral disc cells," Spine, vol. 34, no. 11, pp. 1127-1133, 2009.

[6] M. Valko, D. Leibfritz, J. Moncol, M. T. D. Cronin, M. Mazur, and J. Telser, "Free radicals and antioxidants in normal physiological functions and human disease," The International Journal of Biochemistry \& Cell Biology, vol. 39, no. 1, pp. 4484, 2007.

[7] P. Davalli, T. Mitic, A. Caporali, A. Lauriola, and D. D'Arca, "ROS, cell senescence, and novel molecular mechanisms in aging and age-related diseases," Oxidative Medicine and Cellular Longevity, vol. 2016, Article ID 3565127, 18 pages, 2016.

[8] C. Feng, M. Yang, M. Lan et al., "ROS: crucial intermediators in the pathogenesis of intervertebral disc degeneration," Oxidative Medicine and Cellular Longevity, vol. 2017, Article ID 5601593, 12 pages, 2017.

[9] J. G. Burke, R. W. G. Watson, D. McCormack, F. E. Dowling, M. G. Walsh, and J. M. Fitzpatrick, "Intervertebral discs which cause low back pain secrete high levels of proinflammatory mediators," Journal of Bone and Joint Surgery, British Volume, vol. 84-B, no. 2, pp. 196-201, 2002.

[10] S. Ozkanli, T. Kaner, M. Efendioglu et al., "The relation of matrix metalloproteinase 1, 2, 3 expressions with clinical and radiological findings in primary and recurrent lumbar disc herniations," Turkish Neurosurgery, vol. 25, no. 1, pp. 111116, 2015.

[11] H. Xu, Q. Mei, B. Xu, G. Liu, and J. Zhao, "Expression of matrix metalloproteinases is positively related to the severity of disc degeneration and growing age in the East Asian lumbar disc herniation patients," Cell Biochemistry and Biophysics, vol. 70, no. 2, pp. 1219-1225, 2014.

[12] N. V. Vo, R. A. Hartman, T. Yurube, L. J. Jacobs, G. A. Sowa, and J. D. Kang, "Expression and regulation of metalloproteinases and their inhibitors in intervertebral disc aging and degeneration," The Spine Journal, vol. 13, no. 3, pp. 331-341, 2013.

[13] H. Yu and Y. Zhu, "Expression of ADAMTS-7 and ADAMTS12 in the nucleus pulposus during degeneration of rat caudal intervetebral disc," The Journal of Veterinary Medical Science, vol. 74, no. 1, pp. 9-15, 2012. 
[14] Z. I. Johnson, H. Choi, I. M. Shapiro, and M. V. Risbud, "Disc in flames: roles of TNF- $\alpha$ and IL- $1 \beta$ in intervertebral disc degeneration," Eur Cell Mater, vol. 30, pp. 104-117, 2015.

[15] Y. Zhao, W. Wang, X. Wu et al., "Mangiferin antagonizes TNF-alpha-mediated inflammatory reaction and protects against dermatitis in a mice model," International Immunopharmacology, vol. 45, pp. 174-179, 2017.

[16] S. Saha, P. Sadhukhan, and P. C. Sil, "Mangiferin: a xanthonoid with multipotent anti-inflammatory potential," BioFactors, vol. 42, no. 5, pp. 459-474, 2016.

[17] E. Alberdi, M. V. Sánchez-Gómez, A. Ruiz et al., "Mangiferin and morin attenuate oxidative stress, mitochondrial dysfunction, and neurocytotoxicity, induced by amyloid beta oligomers," Oxidative Medicine and Cellular Longevity, vol. 2018, Article ID 2856063, 13 pages, 2018.

[18] M. Li, C. Wu, H. Guo, C. Chu, M. Hu, and C. Zhou, "Mangiferin improves hepatic damage-associated molecular patterns, lipid metabolic disorder and mitochondrial dysfunction in alcohol hepatitis rats," Food \& Function, vol. 10, no. 6, pp. 3514-3534, 2019.

[19] G. L. Pardo-Andreu, B. A. Paim, R. F. Castilho et al., "Mangifera indica L. extract (Vimang) and its main polyphenol mangiferin prevent mitochondrial oxidative stress in atherosclerosis-prone hypercholesterolemic mouse," Pharmacological Research, vol. 57, no. 5, pp. 332-338, 2008.

[20] Y. Li, Y. Wu, K. Jiang et al., "Mangiferin prevents TBHPinduced apoptosis and ECM degradation in mouse osteoarthritic chondrocytes via restoring autophagy and ameliorates murine osteoarthritis," Oxidative Medicine and Cellular Longevity, vol. 2019, Article ID 8783197, 17 pages, 2019.

[21] Y. Luo, C. Fu, Z. Wang, Z. Zhang, H. Wang, and Y. Liu, "Mangiferin attenuates contusive spinal cord injury in rats through the regulation of oxidative stress, inflammation and the Bcl2 and Bax pathway," Molecular Medicine Reports, vol. 12, no. 5, pp. 7132-7138, 2015.

[22] C. W. A. Pfirrmann, A. Metzdorf, M. Zanetti, J. Hodler, and N. Boos, "Magnetic resonance classification of lumbar intervertebral disc degeneration," Spine, vol. 26, no. 17, pp. 18731878, 2001.

[23] H. Yu, Y. Liu, W. Xie, Q. Xie, Q. Liu, and L. Cheng, "IL-38 alleviates the inflammatory response and the degeneration of nucleus pulposus cells via inhibition of the NF-kappaB signaling pathway in vitro," International Immunopharmacology, vol. 85, article 106592, 2020.

[24] X. Wang, Q. Meng, C. Qiu et al., "Potential therapeutic role of Co-Q10 in alleviating intervertebral disc degeneration and suppressing IL-1beta-mediated inflammatory reaction in NP cells," International Immunopharmacology, vol. 64, pp. 424431, 2018.

[25] Y. Liu, J. Lin, X. Wu et al., "Aspirin-mediated attenuation of intervertebral disc degeneration by ameliorating reactive oxygen species in vivo and in vitro," Oxidative Medicine and Cellular Longevity, vol. 2019, Article ID 7189854, 20 pages, 2019.

[26] Y. Liu, Y. Qu, L. Liu et al., "PPAR-gamma agonist pioglitazone protects against IL-17 induced intervertebral disc inflammation and degeneration via suppression of NF-kappaB signaling pathway," International Immunopharmacology, vol. 72, pp. 138-147, 2019.

[27] Y. Zhao, C. Qiu, W. Wang et al., "Cortistatin protects against intervertebral disc degeneration through targeting mitochondrial ROS-dependent NLRP3 inflammasome activation," Theranostics, vol. 10, no. 15, pp. 7015-7033, 2020.
[28] C. L. Le Maitre, A. J. Freemont, and J. A. Hoyland, "Localization of degradative enzymes and their inhibitors in the degenerate human intervertebral disc," The Journal of Pathology, vol. 204, no. 1, pp. 47-54, 2004.

[29] C. L. Le Maitre, A. Pockert, D. J. Buttle, A. J. Freemont, and J. A. Hoyland, "Matrix synthesis and degradation in human intervertebral disc degeneration," Biochemical Society Transactions, vol. 35, Part 4, pp. 652-655, 2007.

[30] X. Xu, D. Wang, C. Zheng et al., "Progerin accumulation in nucleus pulposus cells impairs mitochondrial function and induces intervertebral disc degeneration and therapeutic effects of sulforaphane," Theranostics, vol. 9, no. 8, pp. 2252 2267, 2019.

[31] W. Hua, S. Li, R. Luo et al., "Icariin protects human nucleus pulposus cells from hydrogen peroxide-induced mitochondria-mediated apoptosis by activating nuclear factor erythroid 2-related factor 2," Biochimica et Biophysica Acta (BBA) - Molecular Basis of Disease, vol. 1866, no. 1, article 165575, 2020.

[32] F. Ding, Z. W. Shao, and L. M. Xiong, "Cell death in intervertebral disc degeneration," Apoptosis, vol. 18, no. 7, pp. 777785, 2013.

[33] Q. Xiang, Z. Cheng, J. Wang et al., "Allicin attenuated advanced oxidation protein product-induced oxidative stress and mitochondrial apoptosis in human nucleus pulposus cells," Oxidative Medicine and Cellular Longevity, vol. 2020, Article ID 6685043, 17 pages, 2020.

[34] Y. P. Zhao, Q. Y. Tian, and C. J. Liu, "Progranulin deficiency exaggerates, whereas progranulin-derived Atsttrin attenuates, severity of dermatitis in mice," FEBS Letters, vol. 587, no. 12, pp. 1805-1810, 2013.

[35] J. Yamamoto, K. Maeno, T. Takada et al., "Fas ligand plays an important role for the production of pro-inflammatory cytokines in intervertebral disc nucleus pulposus cells," Journal of Orthopaedic Research, vol. 31, no. 4, pp. 608-615, 2013.

[36] N. Rand, F. Reichert, Y. Floman, and S. Rotshenker, "Murine nucleus pulposus-derived cells secrete interleukins-1-beta, -6, and -10 and granulocyte-macrophage colony-stimulating factor in cell culture," Spine, vol. 22, no. 22, pp. 2598-2601, 1997.

[37] C. K. Kepler, D. Z. Markova, A. S. Hilibrand et al., "Substance $\mathrm{P}$ stimulates production of inflammatory cytokines in human disc cells," Spine, vol. 38, no. 21, pp. E1291-E1299, 2013.

[38] C. L. Le Maitre, A. J. Freemont, and J. A. Hoyland, “The role of interleukin-1 in the pathogenesis of human intervertebral disc degeneration," Arthritis Research \& Therapy, vol. 7, no. 4, article R732, 2005.

[39] C. L. Le Maitre, J. A. Hoyland, and A. J. Freemont, "Catabolic cytokine expression in degenerate and herniated human intervertebral discs: IL-1beta and TNFalpha expression profile," Arthritis Research \& Therapy, vol. 9, no. 4, article R77, 2007.

[40] C. A. Séguin, R. M. Pilliar, P. J. Roughley, and R. A. Kandel, "Tumor necrosis factor-alpha modulates matrix production and catabolism in nucleus pulposus tissue," Spine, vol. 30, no. 17, pp. 1940-1948, 2005.

[41] M. F. Shamji, L. A. Setton, W. Jarvis et al., "Proinflammatory cytokine expression profile in degenerated and herniated human intervertebral disc tissues," Arthritis and Rheumatism, vol. 62, no. 7, pp. 1974-1982, 2010.

[42] Y. Wang, M. Che, J. Xin, Z. Zheng, J. Li, and S. Zhang, "The role of IL-1beta and TNF-alpha in intervertebral disc 
degeneration," Biomedicine \& Pharmacotherapy, vol. 131, p. 110660, 2020.

[43] C. Wang, X. Yu, Y. Yan et al., "Tumor necrosis factor-alpha: a key contributor to intervertebral disc degeneration," Acta Biochimica et Biophysica Sinica, vol. 49, no. 1, pp. 1-13, 2017.

[44] L. Dai, Z. Liu, W. Liang et al., "Effect of vitamin c on apoptosis of nucleus pulposus cells induced by tumor necrosis factor a and serum deprivation," Zhongguo Xiu Fu Chong Jian Wai Ke Za Zhi, vol. 29, no. 4, pp. 490-497, 2015.

[45] H. Ishibashi, H. Tonomura, T. Ikeda et al., "Hepatocyte growth factor/c-met promotes proliferation, suppresses apoptosis, and improves matrix metabolism in rabbit nucleus pulposus cells in vitro," Journal of Orthopaedic Research, vol. 34, no. 4, pp. 709-716, 2016.

[46] F. Ding, Z. W. Shao, S. H. Yang, Q. Wu, F. Gao, and L. M. Xiong, "Role of mitochondrial pathway in compressioninduced apoptosis of nucleus pulposus cells," Apoptosis, vol. 17, no. 6, pp. 579-590, 2012.

[47] K. A. Campbell, T. Minashima, Y. Zhang et al., "Annexin A6 interacts with p 65 and stimulates NF- $\kappa$ B activity and catabolic events in articular chondrocytes," Arthritis and Rheumatism, vol. 65 , no. 12, pp. 3120-3129, 2013. 